\title{
Governo e Oposição no Senado Brasileiro $(1989-2010)^{*}$
}

\author{
Mauricio Yoshida Izumi
}

Universidade de São Paulo (USP). São Paulo, SP, Brasil. E-mail: mauricio.izumi@usp.br

\section{INTRODUÇÃO}

\begin{abstract}
A área dos estudos legislativos é uma das que mais se desenvolveu nos últimos anos na Ciência Política brasileira. Atualmente, sabemos que as votações nominais possuem uma estrutura unidimensional caracterizada pelo conflito governo e oposição (Leoni, 2002; Zucco, 2009). Contudo, esse diagnóstico diz respeito exclusivamente à Câmara dos Deputados, deixando de lado o Senado Federal. Este artigo busca contribuir para a mudança desse quadro.

O que pretendemos responder é quantas e quais dimensões são necessárias para expressar razoavelmente bem as preferências dos senadores brasileiros. De forma equivalente, será que, assim como na Câmara, as preferências reveladas em votações nominais se distribuem em uma única dimensão que vai de um extremo governista a outro oposicionista? Caso a resposta seja positiva, o que explicaria esse padrão? Entrar ou sair da coalizão de governo altera o comportamento dos senadores? Posto em outros termos, o fato de um partido sair da coalizão governamental faz diferença no comportamento em plenário dos senadores desse partido? Ou será que outras dimensões podem estar presentes? Questões federativas e outras áreas temáticas podem ser relevantes na estrutura de preferências dos senadores?
\end{abstract}

\footnotetext{
*A pesquisa contou com o apoio da Fundação de Amparo à Pesquisa do Estado de São Paulo (Fapesp), processo no 2011/03153-7.

DADOS - Revista de Ciências Sociais, Rio de Janeiro, vol. 59, no 1, 2016, pp. 91 a 138.
} 
Para responder a essas questões utilizaremos técnicas de estimação de pontos ideais baseadas na teoria espacial do voto. Tais técnicas têm sido largamente utilizadas para retratar legislaturas ao redor do mundo (Poole e Rosenthal, 2007; Myagkov e Kiewiet, 1996; Hix e Jun, 2009; Alemán, 2008; Alemán e Saiegh, 2007; Jones e Hwang, 2005; Jones et al., 2008; Leoni, 2002; Zucco, 2009). No entanto, é importante lembrarmos que as técnicas utilizadas para produzir esses retratos foram pensadas inicialmente para o estudo do caso norte-americano, que possui um sistema político bipartidário e no qual as migrações partidárias são eventos raros. Em países como o Brasil, em que o sistema político é multipartidário, no qual as taxas de migrações partidárias não são desprezíveis e mudanças de coalizões também são um fenômeno corrente, algumas precauções devem ser tomadas.

Assim, o segundo objetivo deste artigo é metodológico. Como os pressupostos sobre a distribuição dos erros - sob os quais os modelos paramétricos de estimação de pontos ideais estão baseados - não são factíveis para o caso brasileiro, o uso de técnicas como o W-Nominate e o IDEAL não é recomendável. Dessa maneira, assim como Rosenthal e Voeten (2004), defenderemos o uso do método não paramétrico desenvolvido por Poole (2000), o Optimal Classification (OC).

\section{O DEBATE EM TORNO DAS INSTITUIÇÕES POLÍTICAS BRASILEIRAS}

Nos últimos vinte anos, um longo debate em torno das instituições políticas brasileiras foi travado no interior da ciência política. Para parte da literatura, o sistema político brasileiro é visto como altamente instável e propenso à ingovernabilidade (Abranches, 1988; Ames, 2003; Lamounier, 1994; Mainwaring, 2001). Com a adoção de um sistema de governo presidencialista, um sistema eleitoral proporcional de lista aberta, um pluripartidarismo baixamente institucionalizado, um forte bicameralismo, um federalismo robusto e um Congresso que age como um veto player teríamos como resultado um Poder Executivo fraco que seria obrigado a negociar com um Legislativo indisciplinado e povoado por uma miríade de partidos. Em tal situação, o sistema se tornaria inoperante.

No que se refere ao federalismo, seguindo essa corrente, alguns autores (Abrúcio, 1998; Samuels, 2003) apontam o seu efeito deletério sobre a dinâmica da política nacional. Na visão de Abrúcio (1998), os governadores controlariam importantes recursos para o sucesso eleitoral 
dos deputados federais, que vão desde a distribuição de empregos públicos estaduais e verbas para construção de obras em suas bases locais até o controle de grande parte dos deputados estaduais e prefeitos, que seriam cabos eleitorais fundamentais para a eleição dos deputados federais. Estes, em troca, votariam no Congresso seguindo os interesses do Executivo estadual, e não por questões partidárias, prejudicando, assim, a política nacional. Como punição àqueles que não seguissem as suas ordens na Câmara dos Deputados, o governador, com o auxílio das lideranças políticas locais, criaria novos candidatos que concorreriam às vagas dos parlamentares desobedientes. Tendo em vista essa possibilidade e preocupados com o seu futuro, poucos o desafiariam.

Na mesma linha, Samuels (2003) argumenta que deputados ambicionam posições políticas no governo do estado ou do município, seja antes, seja durante, seja depois do mandato, em vez de construir longas carreiras na Câmara dos Deputados. É dizer, a natureza da ambição política é tal que aqueles que conquistam uma cadeira no Congresso não necessariamente desejam permanecer ali. Pelo contrário, eles preferem ocupar um cargo no Executivo a construir uma trajetória estritamente legislativa. Dado esse desejo, os deputados federais agiriam com o intuito de promover suas próprias carreiras representando o interesse de seus estados e municípios, pois eles sabem que o sucesso de sua carreira depende mais de suas conexões no nível estadual do que conexões com líderes partidários nacionais ou com o presidente. Agindo como advogados de seus distritos, estão também estrategicamente potencializando suas carreiras nesses níveis.

Segundo tal perspectiva teórica, o Poder Executivo federal é obrigado a construir maiorias votação a votação, negociando em um Congresso repleto de parlamentares indisciplinados e individualistas. Estes, por sua vez, cuja ambição política é angariar cargos nos governos estaduais e locais, agiriam estrategicamente em favor dos governos executivos estaduais que detêm importantes recursos organizacionais para suas candidaturas. Em um ambiente como esse, o presidente seria incapaz de implementar políticas inovadoras, pois qualquer tentativa seria barrada por uma minoria sobrerrepresentada e/ou por deputados defensores dos interesses de seus respectivos distritos. A política nacional, dessa maneira, daria lugar aos interesses regionais. Os partidos, como se pôde ver, pouco influenciariam no destino de seus membros no momento anterior à eleição, assim como no pós-eleitoral não controlariam seu comportamento no interior do parlamento. 
Em contraposição a essa corrente, Figueiredo e Limongi (1999) descrevem um cenário muito diferente. Ao analisarem as votações nominais ocorridas na Câmara dos Deputados, os autores sustentam que o Brasil não sofre de crise de governabilidade e que o Executivo não é refém do Congresso. Pelo contrário, o Executivo prepondera sobre o processo legislativo porque tem o domínio sobre a agenda, e esta é trabalhada dentro de um parlamento organizado de forma centralizada, onde o que conta são os partidos. Dentro dessa estrutura institucional, o presidente por meio, principalmente, do controle ao acesso à patronagem, induz os parlamentares à cooperação. Tais parlamentares, assim, não encontram um solo fértil para perseguir interesses individuais, pelo contrário, a melhor opção para a obtenção de recursos visando retornos eleitorais é o voto disciplinado.

Da mesma forma, segundo Arretche (2007), os governos estaduais pouco influenciariam na política nacional e muito menos agiriam como um empecilho para aprovação de matérias no Congresso. As decisões políticas são tomadas no âmbito federal, no qual os únicos pontos de veto são as casas legislativas, que, entretanto, são afetadas pelos recursos institucionais que detêm o presidente e os líderes partidários. Além disso, a União, de acordo com o texto constitucional, possui autoridade para legislar em diversas áreas de competência dos governos subnacionais, limitando novamente essa oportunidade de influenciar negativamente os resultados políticos. Por fim, a aprovação de emendas constitucionais no Brasil é relativamente fácil, sobretudo quando comparada com outros países como os Estados Unidos, onde as alterações necessitam ser confirmadas pela maioria das assembleias estaduais.

Resultados semelhantes foram encontrados por Cheibub, Figueiredo e Limongi (2009). Não obstante os legisladores terem que considerar não apenas suas preferências individuais, como também as de seu eleitorado, as de seus partidos e as dos líderes regionais, o governo federal possui mecanismos que neutralizam essas tendências centrífugas. Portanto, tomar o comportamento dos deputados individuais como moldados pelo poder dos governadores, isto é, que este se sobressaia sobre o poder dos partidos, é um erro, mesmo quando se leva em consideração apenas as matérias de natureza federativa. Os poderes presidenciais e a centralização do processo legislativo em torno dos partidos minimizam as possíveis influências geradas pelo arcabouço institucional brasileiro. 
Em síntese, segundo essa corrente, os presidentes brasileiros são dotados de diversas prerrogativas que lhes dão a capacidade de influenciar diretamente no processo legislativo e induzir os parlamentares à cooperação. Os principais deles são a iniciativa exclusiva de legislação em determinadas áreas estratégicas, o poder de vetar total ou parcialmente projetos, a possibilidade de solicitar urgência e de editar medidas provisórias (Figueiredo e Limongi, 1999; Santos, 2003). Além disso, o chefe do Executivo controla o acesso à patronagem e às emendas ao orçamento (Amorim Neto, 2000; Amorim Neto e Santos, 2001; Pereira e Mueller, 2002; 2003). Isto é, possui o monopólio sobre a distribuição de importantes recursos políticos para a carreira futura dos parlamentares. Por tal razão, alguns autores (Zucco, 2009) chegam a afirmar que, ao transferir tais recursos aos partidos, os presidentes são capazes de deslocar as preferências dos deputados para uma posição mais próxima dos interesses do governo. Ou, numa linguagem espacial, que as votações nominais seguem um padrão unidimensional que vai de um extremo governista a outro oposicionista (Leoni, 2002).

\section{O PAPEL ESQUECIDO DO SENADO}

No entanto, tudo o que foi mencionado aqui diz respeito exclusivamente à Câmara dos Deputados, embora seja comum que os autores estendam as conclusões para o Congresso Nacional como um todo. Estudos sobre o Senado ainda são recentes. Essa ausência, porém, é injustificada. Em primeiro lugar porque, como aponta Neiva (2006), o Senado brasileiro é uma das Câmaras Altas mais fortes do mundo, pois, além de contar com praticamente todas as atribuições exercidas pela Câmara Baixa, tem as prerrogativas exclusivas de aprovar a escolha de diversos membros da alta burocracia; julgar os crimes de improbidade do presidente; suspender a vigência de lei declarada inconstitucional pelo Supremo Tribunal Federal; e trata-se também da única Câmara Alta do mundo com o poder de fixar os limites globais para o montante do endividamento da União, dos Estados, do Distrito Federal e dos Municípios (Neiva, 2004), atribuição que lhe dá enorme capacidade de influência sobre a estabilidade da economia (Loureiro, 2001).

Em segundo lugar, o perfil de deputados e senadores é diferente. Estes últimos fazem parte de uma elite com longas trajetórias políticas. No contexto latino-americano, Llanos e Sánchez (2006) mostraram que os membros das Câmaras Altas são mais velhos, mais educados, mais ri- 
cos e possuem maior experiência política, quando comparados com os membros das respectivas Câmaras Baixas. No caso brasileiro, dentre os senadores titulares, mais da metade já passaram pela Câmara Baixa e quase um terço já foram governadores (Neiva e Izumi, 2012a). Todos os presidentes e vice-presidentes do atual período democrático, com exceção de Luiz Inácio Lula da Silva, Dilma Rousseff e Michel Temer, já passaram pelo Senado Federal, seja antes, seja depois da Presidência (Neiva e Izumi, 2012). O fato de os senadores estarem em um estágio avançado de suas carreiras políticas poderia sugerir uma postura mais independente. Como já mostrou Stratmann (2000), parlamentares mais experientes tendem a votar de forma menos disciplinada em relação à liderança partidária.

Além disso, a organização interna das duas casas também não é igual. Do ponto de vista regimental, o papel exercido pelos líderes partidários no Senado brasileiro é bem menor quando comparado com os da Câmara dos Deputados. Basta lembrarmos que, no Senado, formalmente não existe o Colégio de Líderes e antes de cada votação nominal não há indicação de voto do líder, como ocorre na Câmara (Neiva, 2011a).

Outra diferença relevante diz respeito ao tamanho dos Senados. Em geral, as Câmaras Altas tendem a ser menores (Lijphart, 1999:204). Em realidade, isso é quase uma regra nos sistemas bicamerais. Com 81 membros, o Senado brasileiro corresponde a apenas $16 \%$ do tamanho da Câmara dos Deputados, apresentando-se assim como um dos menores do mundo em termos proporcionais (Neiva, 2004). Uma possível consequência disso seria a forma de se conduzir os trabalhos legislativos. Em ambientes menores, o processo de trabalho seria mais informal e as regras mais flexíveis (Lijphart, 1999:205).

O método de seleção também varia entre as duas casas legislativas. Ao contrário das Câmaras Baixas, muitos Senados são eleitos indiretamente, como na Índia, na Holanda e na Suécia até 1970. Em outros casos, os senadores são indicados, como no Canadá, na Irlanda e na Inglaterra (Lijphart, 1999:206). Entretanto, contemporaneamente, o método que mais tem sido empregado é a eleição direta. Colômbia, Argentina, Croácia, Espanha e Estados Unidos são exemplos disso (Tsebelis e Money, 1997:47). E o Brasil também faz parte desse grupo. Com renovação parcial de um terço e dois terços a cada quatro anos, são eleitos pelo voto popular os 81 senadores. 
Somando-se esse aspecto às suas prerrogativas constitucionais, seguindo a tipologia de Lijphart (1999), podemos afirmar que o bicameralismo brasileiro é simétrico. Em outras palavras, ambas as casas legislativas são dotadas tanto de poderes constitucionais equivalentes, quanto de legitimidade democrática. Como argumentam Llanos e Nolte (2003), essa é uma característica marcante dos regimes bicamerais latino-americanos.

Adicionalmente, tanto o sistema eleitoral quanto a magnitude distrital não são os mesmos. Enquanto os deputados são eleitos pelo sistema proporcional de lista aberta em distritos de magnitude que variam conforme o tamanho da população, os senadores são escolhidos pelo método majoritário em distritos de magnitude igual a três. Em decorrência disso, estes últimos estariam menos propensos a se envolverem em atitudes paroquialistas, ou seja, concentrariam menos a produção legislativa na distribuição de benefícios concentrados (Ricci, 2003).

Outra questão que se torna latente nessa discussão é o tipo de representação, o que equivale a perguntar, "quem é representado?". Quando essa pergunta é feita para a Câmara Baixa, a reposta mais comum é o povo. Isso também é verdadeiro para alguns Senados, como o da Itália e o do Japão de algumas décadas atrás. Em outros lugares, a representação é conferida a categorias profissionais (Irlanda), minorias étnicas (Venezuela) e comunidades linguísticas (Bélgica). Contudo, frequentemente são as unidades subnacionais as representadas. Essa é a característica da maioria dos sistemas federativos, tais como a Áustria, Alemanha, Índia, México e Estados Unidos (Tsebelis e Money, 1997:47-53). E, novamente, o Brasil não foge à regra. Segundo a nossa Constituição, a Câmara dos Deputados representa os interesses do povo, ao passo que o Senado Federal representa os interesses dos estados.

Em geral, casas federativas tendem a sobrerrepresentar pequenas subunidades territoriais, dada a magnitude fixa em igual número. Esse fenômeno, conhecido como desproporcionalidade de representação, ocorre em diversos países, como a Suíça, Venezuela, Austrália e Brasil. Segundo alguns autores (Samuels e Snyder, 2001; Stepan, 1999), o nosso Senado é um dos mais desproporcionais do mundo, atrás apenas do argentino.

O sistema eleitoral, o tipo de representação e sua desproporcionalidade determinam o grau de congruência entre as duas casas. Quando elas distam em sua composição, são denominadas de incongruentes 
(Lijphart, 1999:207). O bicameralismo brasileiro se encaixa nessa categoria. Portanto, na medida em que não representam os mesmos interesses, é razoável imaginar que deputados e senadores atuem de forma diferenciada.

Tomados em conjunto, a simetria, a incongruência e a desproporcionalidade de representação poderiam levar a uma situação de impasse. Na visão de Stepan (1999:217, ênfase no original), "(n)a Câmara Alta brasileira, um grupo de senadores que representa menos de $9 \%$ do eleitorado pode criar um grupo - um 'winset' - capaz de obstruir a aprovação de importantes reformas legislativas". Ou seja, a suposição que está por trás desse argumento é a de que a dimensão que agregaria as preferências dos senadores é a federativa e não a partidária.

Arretche (2010), por sua vez, analisando uma amostra de 32 países argumenta que o bicameralismo é um melhor preditor para a estabilidade constitucional ${ }^{1}$ do que o federalismo. Nesse contexto, o Brasil se apresenta como um interessante estudo de caso. Pois embora possua um bicameralismo forte, ele também possui altas taxas de emendamento constitucional. Investigando esse paradoxo a autora explora o comportamento dos senadores brasileiros nas votações das Propostas de Emenda Constitucional. Os resultados mostram que, diferentemente do que diz Stepan (1999), senadores provenientes de um mesmo estado não votam de forma coesa. Pelo contrário, o que podemos ver são altas taxas de disciplina partidária. Além disso, muitas das propostas aprovadas afetavam negativamente os interesses dos governos subnacionais.

Na mesma linha, Neiva (2011b), em uma análise sistemática de todas as votações nominais ocorridas no plenário do Senado entre 1989 e 2009, argumenta que os partidos são relativamente coesos. Embora, quando comparados com os seus congêneres na Câmara, eles votem de forma menos unida - em média temos $81 \%$ para o Senado, ao passo que para a Câmara temos $85 \%$. Em realidade, a diferença principal se dá mais entre os partidos do que entre as casas (Neiva, 2011a; 2011b). No entanto, mais importante do que isso, Neiva argumenta que a unidade existente no Senado está mais relacionada com coesão do que disciplina partidária.

O tamanho menor, a duração maior do mandato, a renovação parcial e as suas regras internas permitem que o convívio entre os senadores seja mais próximo, permanente, fácil e fluente. A inexistência de um Colé- 
gio de Líderes formalizado, e a presença de um grupo de elite (antigos e futuros governadores e presidentes/vice-presidentes da República) fazem com que a relação entre os líderes partidários e seus liderados seja menos estruturada, menos hierárquica e mais informal. Tudo isto parece contribuir para um grau maior de unidade partidária, a despeito da ausência de uma autoridade central que defina os resultados. Nesse sentido, tal unidade parece ter mais a ver com coesão do que com disciplina (2011a:310).

Resultados semelhantes foram encontrados por Desposato (2006). O autor comparou Câmara e Senado com vistas a avaliar o impacto das regras eleitorais sobre os níveis de coesão partidária. A partir de vários tipos de mensuração, incluindo uma resultante de técnicas de estimação de pontos ideais (W-Nominate), ele chegou à conclusão de que não há diferenças significativas nos níveis de coesão entre as duas Casas. Em ambas eles são altos.

No que diz respeito ao apoio ao governo, segundo Neiva (2011b:194) "os partidos principais agem em função da sua relação com o governo federal, seja ela contrária, seja favorável". Dito de outra forma, os partidos se distribuem espacialmente em uma única dimensão que expressa o conflito entre governo e oposição. No entanto, como os partidos não são totalmente disciplinados (Neiva, 2011a; 2011b), o ideal seria estimar a posição de cada senador individualmente e não apenas dos agregados partidários. Além disso, o autor (Neiva, 2011a; 2011b) não verificou a existência de outras possíveis dimensões.

\section{ASPECTOS METODOLÓGICOS}

Os dados utilizados neste artigo serão as votações nominais do banco de dados legislativos do Centro Brasileiro de Análise e Planejamento (Cebrap). Mesmo que haja limitações ${ }^{2}$ em se trabalhar com votações nominais, não podemos deixá-las de lado na análise do comportamento político, já que nelas somos capazes de enxergar as preferências manifestas dos legisladores, cuja agregação é que decidirá o resultado de uma política.

Para recuperar as dimensões do espaço político utilizarei técnicas de estimação baseadas em modelos espaciais do voto (Enelow e Hinich, 1984; Hinich e Munger, 1997). O modelo espacial assume que as alternativas políticas podem ser representadas como pontos em um espaço euclidiano - uma linha, plano ou hiperplano. Legisladores, por sua 
vez, possuem preferências definidas sobre essas alternativas (McCarty, 2011:3). Em geral, é assumido que essas preferências são de pico único (single-peakedness). Quer dizer, de todas as alternativas políticas possíveis, apenas uma delas é a preferida pelo legislador. Dizemos que ela é o seu ponto ideal. Assim, cada parlamentar possui somente um ponto ideal. Assume-se também que as preferências são simétricas, ou seja, se existe duas alternativas políticas equidistantes do ponto ideal do legislador, ele é indiferente às duas propostas. Esse pressuposto é bastante restritivo (Hinich e Munger, 1997:27-29). Isso porque ele exclui formas plausíveis de preferências políticas. Por exemplo, a redução em 5\% dos impostos pode ser algo muito mais importante para um parlamentar do que um aumento da mesma magnitude. É razoável imaginar que ele não seja indiferente às duas propostas.

Nos últimos trinta anos, diversos modelos probabilísticos de voto legislativo foram desenvolvidos com base nessas ideias. Em modelos desse tipo, a utilidade de um parlamentar é composta pela soma de uma porção determinística e de uma porção estocástica. Assim, sendo i o número de parlamentares $(i=1, \ldots, p)$ e j o número de votações $(j=1, \ldots$, q), a utilidade de um parlamentar i para a consequência "Sim" em uma votação j pode ser expressa por:

$$
\mathrm{U}_{\mathrm{ijs}}=\mathrm{u}_{\mathrm{ijs}}+\mathrm{e}_{\mathrm{ijs}}
$$

De forma equivalente, a utilidade para a consequência "Não" será:

$$
\mathrm{U}_{\mathrm{ijn}}=\mathrm{u}_{\mathrm{ijn}}+\mathrm{e}_{\mathrm{ijn}}
$$

em que $u_{i j s}$ e $u_{i j n}$ são as porções determinísticas das funções de utilidade $\mathrm{e}_{\mathrm{ijs}} \mathrm{e}_{\mathrm{ijn}}$ são as porções estocásticas.

Se o voto for perfeito, um legislador i votará "Sim" em uma votação j se $\mathrm{U}_{\mathrm{ijs}}-\mathrm{U}_{\mathrm{ijn}}>0$. Entretanto, como os erros não são observados, algum pressuposto sobre a sua distribuição deve ser feita. Tendo isso em mãos, podemos calcular a probabilidade de um legislador votar "Sim" (Poole, 2005:89):

$$
\mathrm{P} \text { (legislador i votar "Sim" em uma votação j })=P\left(U_{\mathrm{ijs}}-\mathrm{U}_{\mathrm{ijn}}>0\right)
$$

Os dois principais modelos são o W-Nominate (Poole e Rosenthal, 1985; 1991; 2007) e o IDEAL (Clinton, Jackman e Rivers, 2004). No primeiro, a forma funcional (porção determinística) segue a distribuição 
normal e os erros (porção estocástica) seguem a distribuição logística. Já no IDEAL, a forma funcional é quadrática e os erros seguem a distribuição normal (Carrol et al., 2013).

Como argumentam Rosenthal e Voeten (2004:621), modelos paramétricos, como o W-Nominate e o IDEAL, "assumem que os erros são independentes e identicamente distribuídos (i.i.d.) entre os legisladores e as votações". Ou seja, a variância do erro deve ser homocedástica. Embora esse pressuposto seja factível para o Congresso norte-americano, para o qual tais técnicas foram desenvolvidas e largamente testadas, ele pode não ser apropriado para o contexto de outras legislaturas. Por exemplo, o Senado brasileiro.

Um primeiro ponto diz respeito à disciplina partidária. Se alguns legisladores estão mais sujeitos a uma forte pressão do partido do que outros, o pressuposto de que os erros são i.i.d. é provavelmente violado (Rosenthal e Voeten, 2004:621). Como os dados de Neiva (2011a) mostram, a disciplina entre os partidos na Câmara Alta brasileira varia de maneira significativa. Enquanto alguns partidos, como o $\mathrm{PT}^{*}$, são extremamente coesos/disciplinados, outros, como o PMDB, possuem índices não tão altos.

Em segundo lugar, a migração partidária é outro problema. Obviamente, se os parlamentares não alterarem o seu comportamento ao migrar de partido, não há problema algum. Mas, se eles migram de um partido mais disciplinado para um menos disciplinado e, assim, tornam-se sujeitos a uma maior pressão partidária nas votações, o pressuposto é violado. Mais importante do que isso, é razoável imaginar que mudar de partido altera o ponto ideal do parlamentar (Rosenthal e Voeten, 2004:621). E o mesmo argumento pode ser estendido para a entrada / saída de um partido da coalizão de governo. Mesmo que o parlamentar não tenha migrado de partido, sabemos que a orientação do partido e consequentemente do parlamentar pode ser completamente diferente.

Por fim, o comportamento estratégico é um terceiro fator que viola o pressuposto (ibidem:622). Votar estrategicamente está aqui em contraposição à ideia de voto sincero. Isso implica que, se um parlamentar está diante de duas alternativas políticas, não necessariamente ele votará naquela que está mais próxima de seu ponto ideal. Legisladores

\footnotetext{
*Ver lista de siglas dos partidos políticos com os respectivos significados ao final do artigo.
} 
que votam, digamos, com os interesses de seus estados e não com os do partido, violam sistematicamente o pressuposto de i.i.d. Isso porque parlamentares com determinadas características (vamos dizer, por exemplo, provenientes de estados pobres) são mais propensos a votar estrategicamente do que os outros.

Com vistas a minimizar esses problemas será utilizada aqui a técnica não paramétrica do Optimal Classification (Poole, 2000). Essa técnica, ao contrário do W-Nominate e do IDEAL, não é sustentada sobre qualquer pressuposto sobre a forma funcional das preferências dos legisladores e a distribuição dos erros ${ }^{3}$. O OC busca encontrar os pontos ideais dos legisladores e os cutpoints das votações que minimizam o número de erros. Ou seja, ele maximiza a classificação correta das escolhas legislativas (Poole, 2000:212).

O procedimento consiste em três etapas (Poole, 2005:82):

1. Gera valores iniciais para os parlamentares a partir da decomposição em autovalores e autovetores da matriz de concordância senador-senador.

2. Dados os pontos ideais dos parlamentares, para cada votação é encontrado um plano de corte que maximiza a classificação correta dos votos dos parlamentares.

3. Dados os planos de corte das votações, para cada parlamentar é encontrado um ponto no espaço que maximiza a classificação correta dos votos dos parlamentares.

4. Retorna para a etapa 2.

Nesse processo iterativo, o número de classificações corretas nunca diminui, e as etapas 2 e 3 podem se repetir até que nenhum ganho em classificações corretas seja mais possível (Poole, 2000:212).

As estimativas geradas pelo Optimal Classification são altamente semelhantes às produzidas pelas outras técnicas paramétricas (W-Nominate e IDEAL). No entanto, com a vantagem de não fazer nenhuma pressuposição acerca da forma funcional da utilidade dos parlamentares e da distribuição dos erros.

Serão utilizadas todas as votações nominais ocorridas no plenário do Senado Federal entre janeiro de 1989 e agosto de 2010. Temos ao todo seis legislaturas, sob o governo de cinco presidentes diferentes e a formação de 19 coalizões (ver Anexo 1). Durante esse período ocorreram 
1.408 votações nominais, com a participação de 362 senadores, e foram dados 80.640 votos.

O Optimal Classification exclui todas as votações em que não houve conflito. Ou seja, todas aquelas em que $97,5 \%$ do plenário votou de forma igual serão excluídas ${ }^{4}$. Além disso, ele inclui apenas os parlamentares que votaram ao menos vinte vezes em cada período estudado - neste caso, por legislatura. Uma importante decisão a ser tomada nesse momento é a escolha da unidade de análise. Poole e Rosenthal (2007), para o caso norte-americano, utilizam o parlamentar por partido. Isto é, se um democrata migrar para o partido republicano, entrará com dois registros. É como se ele fosse dois indivíduos diferentes. Essa escolha assume que todos os congressistas que não migraram de partido, incluindo aqueles que foram da Câmara para o Senado, possuem posições ideológicas estáveis ao longo do tempo (Poole, 2007:438). De acordo com alguns autores (Nokken, 2000; Nokken e Poole, 2004; McCarty, Poole e Rosenthal, 2001), mudanças partidárias são casos claros em que mudanças ideológicas ocorrem. Leoni (2002:367), para o caso brasileiro, adota o indivíduo no "retrato" do partido. Basicamente, é o deputado no partido pelo qual ele votou pela primeira vez na legislatura. Porém, dada a questão da migração partidária, acreditamos que essa escolha seja um pouco problemática. Lembremos que, ao contrário dos Estados Unidos, no Brasil a troca de partidos não é um fenômeno raro ${ }^{5}$ (Desposato, 2005; Freitas, 2012; Melo, 2004). Por exemplo, vamos supor que um senador do PDT, durante o primeiro mandato do governo Lula, migre para o PSDB. Suponhamos também que o PDT faça parte da coalizão do governo e o PSDB faça oposição. Se considerarmos o parlamentar em questão unicamente em um ou em outro partido, estaríamos cometendo um equívoco relativamente grave. Sobretudo se tivermos em vista, como sugere grande parte da literatura (Figueiredo e Limongi, 1999; Leoni, 2002; Neiva, 2011b; Zucco, 2009), que o pertencimento ou não à coalizão governamental é um fator determinante do comportamento legislativo.

Testamos três tipos de agregação. O primeiro é o modelo básico no qual cada senador entra apenas uma única vez na base de dados. Esse modelo assume que os parlamentares possuem pontos ideais estáveis ao longo da legislatura e, portanto, mesmo ao migrarem de partido, mantêm as suas posições durante todo o período. O segundo é o modelo de migração partidária. Nele assumimos que apenas os parlamentares que continuaram durante toda a legislatura no mesmo partido pos- 
suem pontos ideais estáveis. Assim, todos aqueles que migraram possuem mais de um ponto ideal. O terceiro modelo, o de mudança de coalizão, por sua vez, assume que parlamentares que se mantiveram sempre na coalizão ou na oposição possuem pontos ideais estáveis. Mesmo que tenham migrado de partido, como permaneceram na coalizão ou na oposição, possuem somente um ponto ideal. Para ser mais claro, se um parlamentar que está em um partido governista migrar para um partido que também faça parte da coalizão, o parlamentar entra apenas uma vez em nossa base de dados. Contudo, se ele migrar para um partido que seja da oposição, ele entrará com dois registros. Da mesma forma, se um parlamentar estiver em um partido da base do governo que em certo momento sair, o parlamentar em questão também terá dois registros.

Como vemos pela Tabela 1, o modelo básico, como esperado, é o que possui menos senadores votantes. Ele possui em média 107,2 parlamentares por legislatura. Em seguida vem o modelo de migração partidária,

Tabela 1

Senadores Incluídos por Modelo

\begin{tabular}{|c|c|c|c|}
\hline Legislatura & Modelo & Senadores Votantes & Senadores Incluídos \\
\hline \multirow{3}{*}{$48^{-\mathrm{a}}$} & Básico & 93 & $54(58,1 \%)$ \\
\hline & Migração partidária & 124 & $39(31,5 \%)$ \\
\hline & Mudança de coalizão & 131 & $27(20,6 \%)$ \\
\hline \multirow{3}{*}{$49^{-\mathrm{a}}$} & Básico & 105 & $92(87,6 \%)$ \\
\hline & Migração partidária & 132 & $107(81,1 \%)$ \\
\hline & Mudança de coalizão & 165 & $132(80,0 \%)$ \\
\hline \multirow{3}{*}{$50^{-\mathrm{a}}$} & Básico & 112 & $89(79,5 \%)$ \\
\hline & Migração partidária & 134 & $103(76,9 \%)$ \\
\hline & Mudança de coalizão & 129 & $101(78,3 \%)$ \\
\hline \multirow{3}{*}{$51^{\mathrm{a}}$} & Básico & 116 & $93(80,2 \%)$ \\
\hline & Migração partidária & 148 & $111(75,0 \%)$ \\
\hline & Mudança de coalizão & 147 & $113(76,9 \%)$ \\
\hline \multirow{3}{*}{$52^{-a}$} & Básico & 108 & $86(79,2 \%)$ \\
\hline & Migração partidária & 135 & $86(63,7 \%)$ \\
\hline & Mudança de coalizão & 144 & $107(74,3 \%)$ \\
\hline \multirow{3}{*}{$53^{\mathrm{a}}$} & Básico & 109 & $78(71,6 \%)$ \\
\hline & Migração partidária & 122 & $76(62,3 \%)$ \\
\hline & Mudança de coalizão & 125 & $77(61,6 \%)$ \\
\hline
\end{tabular}

Fonte: Banco de dados legislativos (Cebrap). 
com uma média de 132,5. E, por fim, o modelo de mudança de coalizão, com uma média de 140,2. Isso sugere que o modelo básico é o mais parcimonioso, ou seja, o que possui menos parâmetros a serem estimados. Olhando para o número médio de senadores incluídos - isto é, para o número de parlamentares que efetivamente entrarão na estimação - o modelo básico continua sendo aquele com o menor número de parlamentares. No entanto, a diferença média do número de senadores incluídos entre os modelos é muito pequena (82 para o modelo básico; 87 para o de migração partidária; e 92,8 para o de mudança de coalizão). Dada essa diferença reduzida, utilizaremos aqui o modelo de mudança de coalizão por ser o mais flexível e com maior sustentação teórica.

No que diz respeito às votações nominais, cerca de metade $(52,8 \%)$ foram incluídas. Dito de outra forma, 47,2\% das votações foram excluídas porque não sobreviveram aos critérios adotados. Assim, trabalharemos com 744 das 1.408 votações (Tabela 2).

Tabela 2

Votações Nominais Incluídas

\begin{tabular}{l|c|c}
\hline Legislatura & Votações Nominais & Votações Incluídas \\
\hline $48^{\mathrm{a}}$ & 45 & $35(77,8 \%)$ \\
$49^{\mathrm{a}}$ & 179 & $126(70,4 \%)$ \\
$50^{\mathrm{a}}$ & 514 & $264(51,4 \%)$ \\
$51^{\mathrm{a}}$ & 280 & $158(56,4 \%)$ \\
$52^{-\underline{a}}$ & 222 & $99(44,6 \%)$ \\
$53^{\mathrm{a}}$ & 168 & $62(36,9 \%)$ \\
\hline Total & $\mathbf{1 . 4 0 8}$ & $\mathbf{7 4 4}$ \\
\hline
\end{tabular}

Fonte: Banco de dados legislativos (Cebrap).

\section{DIMENSIONALIDADE E AJUSTE DO MODELO}

O problema da dimensionalidade do espaço político não é novo. Um de seus maiores precursores foi Black (1958). Segundo ele, em contextos unidimensionais existe um equilíbrio único e que se dá na posição mediana ${ }^{6}$. Ou seja, em decisões tomadas pela regra da maioria, aquele que está nessa posição nunca perde ${ }^{7}$. Mas o mesmo não ocorre em ambientes multidimensionais.

Em teoria, a existência da multidimensionalidade não é um fenômeno raro. Se entendermos o número de dimensões como o número de áreas temáticas relevantes para os atores (Leoni, 2002:362), é plausível supor 
que diferentes atores poderiam ter avaliações ou preferências distintas no que diz respeito a diferentes áreas da política. Isto é, que as preferências podem variar independentemente umas das outras. Esse fato tornaria o espaço político multidimensional. Seguindo parte da literatura que estudou o congresso brasileiro (Ames, 2003; Lamounier, 1994; Mainwaring, 2001), mesmo se levássemos em conta os incentivos existentes no sistema político e deixássemos de lado as preferências dos legisladores estaríamos diante de um plano multidimensional. Isso porque os incentivos do sistema político brasileiro seriam centrífugos, decorrentes, sobretudo, do forte federalismo (Abrúcio, 1998; Samuels, 2003).

Quando estamos diante de um plano com mais de uma dimensão, a mesma previsibilidade que temos em espaços unidimensionais desaparece, o caos se instaura e tudo pode acontecer (McKelvey, 1976). Nesse momento, a questão do número de dimensões passa a ser relevante.

Mas como determinar o número de dimensões a ser estimado? Na visão de Poole (2005:141), é mais uma questão substantiva do que estatística. Não há nenhuma técnica que seja crucial na escolha entre um modelo unidimensional ou multidimensional. Uma sugestão, porém, é olhar para o ajuste do modelo. Como é possível observar na Tabela 3, com apenas uma dimensão o Optimal Classification classificou corretamente pelo menos $90,7 \%$ das votações (49a legislatura). Isso não é um valor baixo, principalmente se compararmos com o resultado encon-

Tabela 3

Classificação Correta e Redução Proporcional do Erro Agregado (APRE)

\begin{tabular}{c|c|c|c}
\hline Legislatura & Dimensões & CC & APRE \\
\hline \multirow{2}{*}{$48^{\text {a }}$} & 1 & 94,8 & 0,81 \\
& 2 & 98,5 & 0,94 \\
\hline \multirow{2}{*}{$49^{\text {a }}$} & 1 & 90,7 & 0,5 \\
& 2 & 93,7 & 0,66 \\
\hline \multirow{2}{*}{$50^{\text {a }}$} & 1 & 91,9 & 0,61 \\
& 2 & 93,2 & 0,67 \\
\hline \multirow{2}{*}{$51^{\text {a }}$} & 1 & 92,1 & 0,58 \\
& 2 & 94 & 0,68 \\
\hline \multirow{2}{*}{$52^{\text {a }}$} & 1 & 91,8 & 0,67 \\
& 2 & 93,8 & 0,75 \\
\hline \multirow{2}{*}{$53^{\text {a }}$} & 1 & 94 & 0,77 \\
& 2 & 96,4 & 0,86 \\
\hline
\end{tabular}

Fonte: Banco de dados legislativos (Cebrap). 
trado para a Câmara dos Deputados no mesmo período (90,5\%). E mesmo com o Senado norte-americano. Durante a 102a legislatura (1991-1992), o modelo unidimensional classificou corretamente $87,0 \%$ das votações, e 89,3\% para a 103 legislatura (1993-1994).

Além da porcentagem de classificações corretas também precisamos ver a APRE. Visto que o primeiro ajuste, por si só, tende a gerar estimativas inflacionadas pelas votações em que uma maioria supera largamente a minoria. Por exemplo, vamos supor que, em uma votação, $90 \%$ do plenário vote "Sim" e os 10\% restante vote "Não". Se nós escolhêssemos aleatoriamente um parlamentar, a probabilidade de classificar corretamente o seu voto é de 90\% (Poole, 2005:129).

Para não cair nessa predição ingênua criou-se a medida APRE ${ }^{8}$. Ela varia de zero a um. Quando seu valor é igual a zero significa que o modelo não explica nada. Por outro lado, se atinge o valor igual a um, uma classificação perfeita foi alcançada.

Pela Tabela 3, como é de se esperar, em todas as situações a APRE com duas dimensões foi mais alta do que com uma. Em especial, a legislatura de número 49 é a que possui o melhor ganho com duas dimensões. $\mathrm{O}$ modelo unidimensional possui uma APRE de 0,50, ao passo que um modelo com duas dimensões alcança o valor de 0,66. Comparando mais uma vez com a Câmara dos Deputados, encontramos os seguintes valores: 0,63 e 0,70 , com uma e duas dimensões, respectivamente. E para o Senado americano temos 0,59 (uma dimensão) e 0,64 (duas dimensões) para a 102a legislatura e 0,67 (uma dimensão) e 0,72 (duas dimensões) para 103a legislatura. Nas outras legislaturas também há uma melhora no ajuste, embora não ultrapassem 0,13 . Vê-se que, em geral, o ganho não é muito grande.

Em resumo, o que podemos concluir a partir dos ajustes é que com apenas uma dimensão podemos representar razoavelmente bem as votações nominais de nossa Câmara Alta. A questão agora é saber qual é o conteúdo substantivo dessa dimensão. A seção que se segue busca iluminar isso.

\section{O CONTEÚDO DA $1^{\mathrm{a}}$ DIMENSÃO}

Para o caso norte-americano, Poole e Rosenthal (2007) sustentam que o conteúdo da primeira dimensão é a ideologia. Ou seja, durante quase toda a história americana os parlamentares se distribuíram ao longo de um contínuo que ia de um extremo conservadorismo a um extremo li- 
beralismo. Somente em alguns períodos é que a segunda dimensão pareceu ser relevante ${ }^{9}$. No contexto latino-americano, resultados semelhantes foram encontrados para o caso chileno (Alemán, Saiegh, 2007; Alemán, 2008). Tanto para a Câmara, quanto para o Senado do período recente, há uma forte cisão entre as duas principais coalizões do país Concertación e Alianza. É importante notar que os autores não distinguem ideologia de coalizão, justamente porque as duas coisas estão altamente correlacionadas. Para os casos argentino (Jones e Hwang, 2005; Jones, Hwang e Micozi, 2008) e uruguaio (Altman, 2000; Zucco, 2013), a despeito das afinidades ideológicas dos parlamentares, observamos uma clara divisão entre governistas e oposicionistas. Para o Brasil, o trabalho pioneiro foi o de Leoni (2002). Segundo ele, o conteúdo da primeira dimensão também é dado pelo conflito governo versus oposição. Ou seja, os deputados se dividem entre aqueles que dão um apoio incondicional ao governo e aqueles que se opõem totalmente às suas propostas, com diversos graus entre eles.

Nas figuras 1 e 2 apresentamos os pontos ideais estimados dos senadores brasileiros ${ }^{10}$. Como veremos, o conflito entre governo e oposição é o que tem dividido os senadores brasileiros no pós-Constituinte. De um lado, aqueles que dão o seu apoio ao governo e, do outro, aqueles que se opõem.

$\mathrm{Na} 48^{\mathrm{a}}$ legislatura, poucos senadores tiveram seus pontos ideais estimados - cerca de $20 \%$. Mesmo assim, alguns comentários podem ser feitos. Em primeiro lugar, vemos que o PFL é razoavelmente coeso e está consistentemente à direita do espectro. O PDC, embora não fizesse parte da coalizão formal do governo, deu grande parte de seus votos a

Figura 1

Optimal Classification - 48 ${ }^{\mathrm{a}}$ Legislatura (1989-1990)

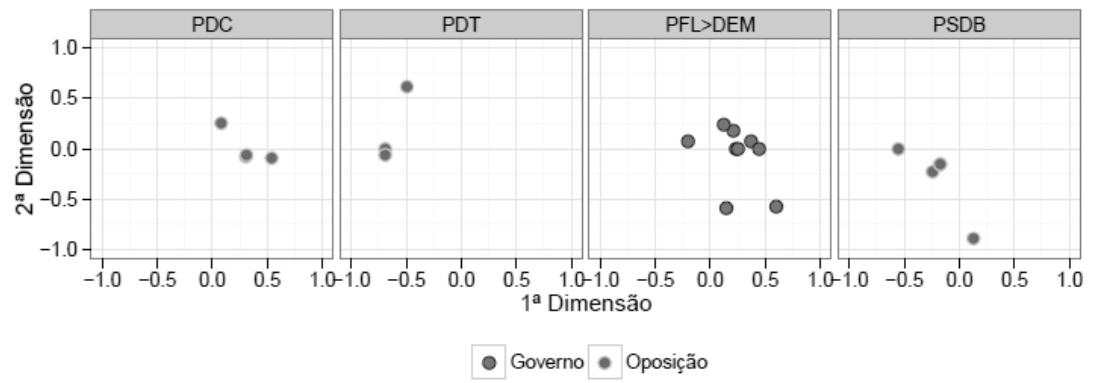

Fonte: Banco de dados legislativos (Cebrap). 
Figura 2

Optimal Classification - 49 Legislatura (1991-1994)

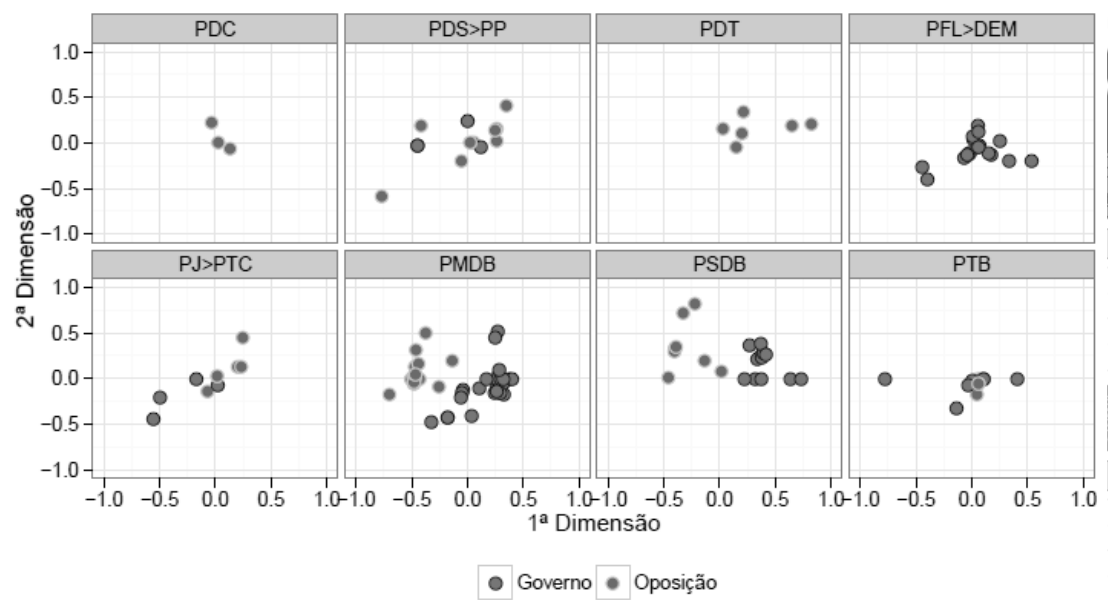

Fonte: Banco de dados legislativos (Cebrap).

ele. Os senadores do PDT, por sua vez, estão fortemente concentrados mais à esquerda. Por fim, o PSDB parece estar em uma posição um pouco mais oscilante. Embora fosse um partido de esquerda, ele é relativamente menos coeso do que os outros partidos do mesmo lado do espectro ideológico.

Na 49a legislatura, em geral, os pontos ideais estão bem espalhados ao longo do mapa espacial. PDC, PDT e PFL são as exceções. No entanto, o que é interessante notar é a diferença de posição entre os governistas e os oposicionistas no interior dos partidos. No PMDB e no PSDB isso é nítido.

As estimativas geradas para a 49a legislatura são menos precisas. Sobretudo porque nesse período tivemos dois presidentes com posições muito diferentes, assim como coalizões radicalmente muito distintas. Lembremos que durante a vigência dessa legislatura, o então presidente Fernando Collor sofreu um processo de impeachment após denúncias de corrupção e renunciou ao cargo em 29 de dezembro de 1992, assumindo em seu lugar o seu vice, Itamar Franco. Em outras palavras, temos dois presidentes em uma única legislatura. Sendo que das 179 votações ocorridas no período, em torno de 35\% ocorreram sob o governo de Collor e o restante sob o de Itamar.

Para ilustrar esse efeito da mudança presidencial sobre o comportamento legislativo, na Figura 3 agrupo os dados tendo como unidade de 
análise o senador / presidente - ou seja, todos os senadores entram com dois registros, um sob o governo Collor e outro sob o governo Itamar. A princípio, do ponto de vista metodológico, esse teste não seria possível já que estaríamos comparando dois mapas espaciais que não são estritamente comparáveis, pois são frutos de duas matrizes de votações completamente distintas (Poole, 2005:165). Isto é, se não houver um claro ponto de referência para colocá-los em um mesmo espaço, eles não são comparáveis (Bailey, 2007:434). É como se quiséssemos comparar as notas de alunos que fizeram uma prova de matemática com as de alunos que fizeram uma prova de português. Para que a comparação seja factível precisamos da sobreposição de alguns alunos. No nosso caso, essa questão é facilmente resolvida com a utilização de parlamentares como "pontes", ou seja, parlamentares que entram com apenas um registro na base de dados e assim servem como ligação entre os dois mapas (Shor, Berry e McCarty, 2010).

Para o nosso caso, utilizamos como ponte os senadores do PT e do PDT. Esse subconjunto de parlamentares se mostrou adequado pois sabemos que, durante todo esse período, ambos partidos estavam formalmente fora da coalizão. O que equivale a dizer que possuem pontos ideais estáveis ao longo dos dois governos. Sendo assim, podemos compará-los.

Como vemos (Figura 3), há uma forte divisão na primeira dimensão entre as estimativas geradas para os senadores antes e depois da mudança presidencial ocorrida nessa legislatura. Sob o governo Collor,

Figura 3

\section{Collor x Itamar}

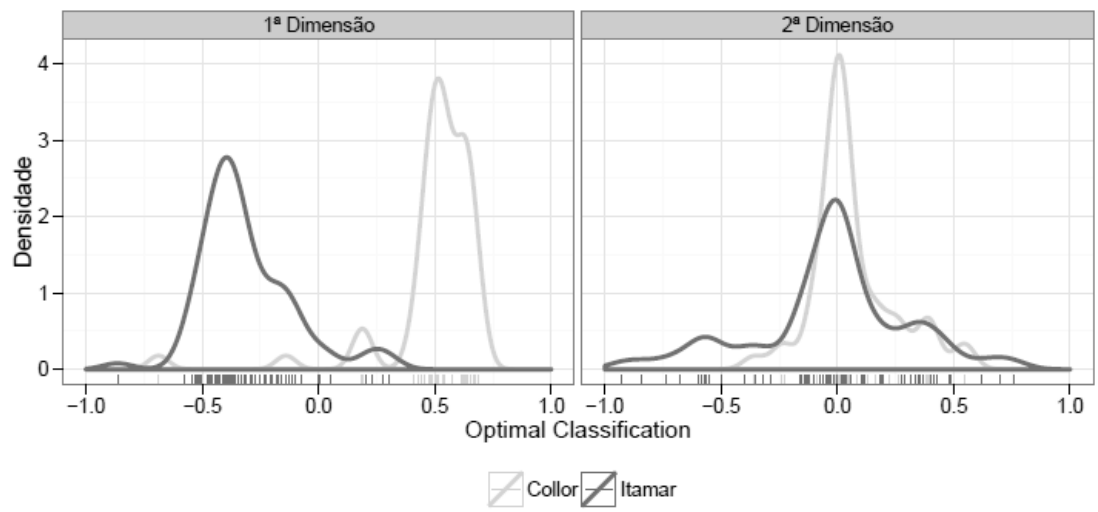

Fonte: Banco de dados legislativos (Cebrap). 
mais de $96 \%$ dos senadores possuem pontos ideais com valores positivos e, sob o governo Itamar, 91\% dos mesmos senadores estão do lado oposto (com pontos ideais com valores negativos). Ou seja, a existência de dois presidentes está influenciando diretamente as estimativas. Mas o mesmo não ocorre para a segunda dimensão. Nela, a distribuição dos pontos segue um padrão semelhante tanto para o governo Collor quanto para o governo Itamar. Ambas as distribuições se concentram no centro da escala.

O que explica esse padrão encontrado? Se lembrarmos que no Brasil os presidentes são dotados de fortes poderes de agenda, somos capazes de compreender melhor isso. Como mostram Figueiredo e Limongi (2000:155), 86\% das leis sancionadas entre 1989 e 1997 foram introduzidas pelos presidentes, e a taxa global de projetos aprovados com origem no Executivo é de 78\%. Ao controlar a agenda, o Executivo está apto a determinar o que será votado e quando o será. Ao possuírem essa prerrogativa, presidentes alteram a localização das políticas no espaço no qual os legisladores irão agir.

Na 50a legislatura (Figura 4), o conflito entre governo e oposição ficou mais evidente. De um lado, os senadores que faziam parte da base de apoio, do outro, aqueles que não faziam. Outra coisa que se nota é a baixa dispersão interna a alguns partidos. Parece que, a partir do governo Fernando Henrique, surge um padrão mais claro e estável, que

Figura 4

Optimal Classification - 50를 Legislatura (1995-1998)

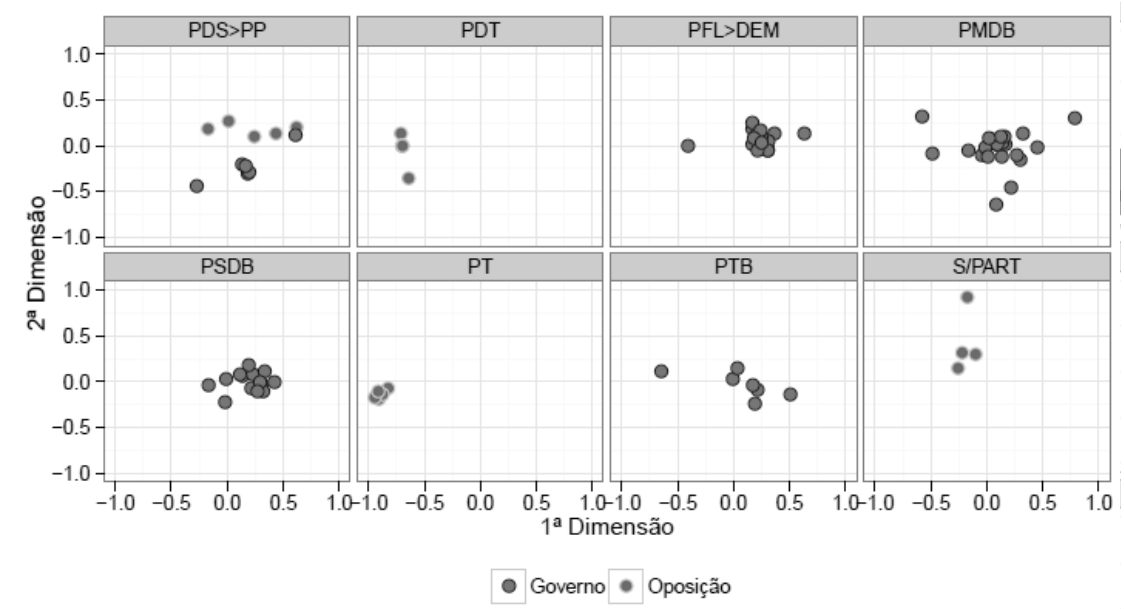

Fonte: Banco de dados legislativos (Cebrap).

DADOS - Revista de Ciências Sociais, Rio de Janeiro, vol. 59, no 1, 2016 
pode estar relacionado com a estabilização econômica ocorrida a partir de 1994.

Olhando para cada um dos partidos, vemos que o PMDB se distribui praticamente por toda a escala. No PFL apenas o senador Josaphat Marinho (PFL/BA) é que se distancia do seu grupo. Mas, no geral, o partido é bastante coeso, assim como o PT e o PDT. O PT em particular está bem no extremo esquerdo do mapa espacial, com um grande número de pontos sobrepostos. Isso é explicado, de um lado, pela alta disciplina partidária, de outro, pela baixa diferenciação que o OC faz entre os extremistas. Mas o principal a ser destacado é a clara divisão entre os parlamentares de partidos que estão na base do governo e os parlamentares de partidos que estão na oposição. O que se nota é uma clara polarização entre o principal partido de oposição (PT) e o partido do presidente (PSDB).

Com relação ao PDS ocorreu algo interessante. Ele entrou para a coalizão apenas em abril de 1996, na segunda coalizão de Fernando Henrique. Contudo, mesmo quando não fazia parte da coalizão formal, votou consideravelmente com os partidos governistas.

De maneira geral, durante a 51a legislatura (Figura 5), os partidos da oposição agiram como tal. Ao longo da primeira dimensão, PCB, PDT, PSB e PT estão muito próximos uns dos outros, à esquerda da escala, com uma dispersão muito baixa. A exceção é o PTB que, do ponto de vista formal, era um partido de oposição, mas votou significativamente com os partidos governistas. Já o PFL, que saiu da coalizão no início de março de 2002, apresenta uma clara mudança de comportamento. Quando fazia parte da coalizão de governo, os senadores desse partido possuíam pontos ideais muito semelhantes aos dos senadores do partido do presidente (PSDB). Ao sair da coalizão houve um deslocamento mais à esquerda, onde estavam os partidos de oposição.

Na 52a legislatura (Figura 6), o PMDB entrou para o governo na segunda coalizão do presidente Lula, em janeiro de 2004. No entanto, mesmo antes dessa data, boa parte do PMDB já dava seu apoio ao governo. Mas também vemos que alguns senadores desse partido, mesmo após a entrada para base, continuaram a se opor à agenda presidencial. $\mathrm{O}$ PDT, por sua vez, percorreu o caminho inverso, saindo da base de governo a partir da segunda coalizão. E, como podemos observar, mesmo quando era governo, pouco apoiou Lula. Já PSDB e PFL, os principais partidos de oposição, fizeram seu papel. 
Figura 5

Optimal Classification - 51 ${ }^{\mathrm{a}}$ Legislatura (1999-2002)

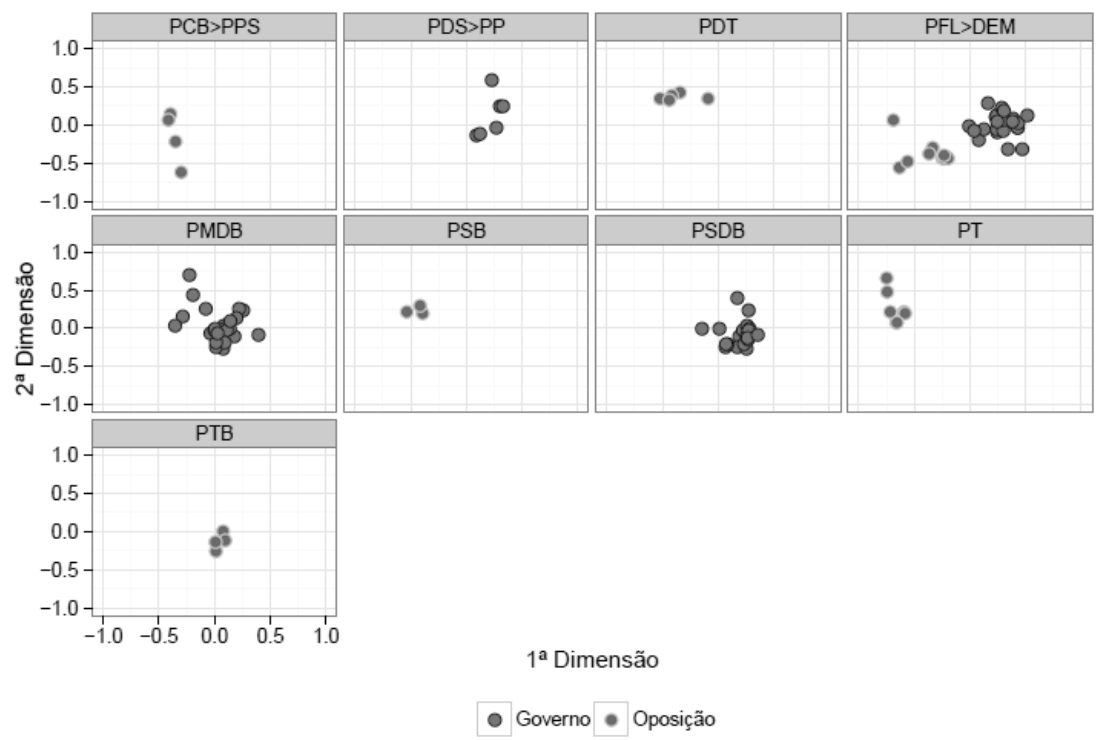

Fonte: Banco de dados legislativos (Cebrap).

Figura 6

Optimal Classification - 52 ${ }^{\mathrm{a}}$ Legislatura (2003-2006)

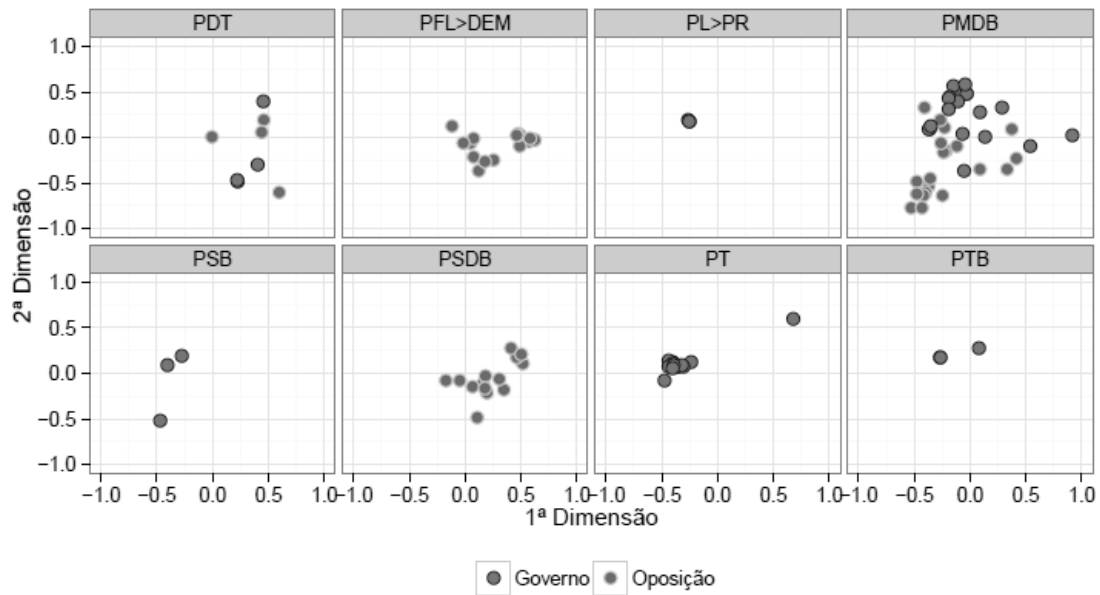

Fonte: Banco de dados legislativos (Cebrap).

DADOS - Revista de Ciências Sociais, Rio de Janeiro, vol. 59, nº 1, 2016 
Os demais partidos apoiaram o governo. O único ponto a ressaltar diz respeito ao PT, conhecido pelos seus altos níveis de coesão e disciplina, em que se vê um ponto ideal distante do resto do grupo. Esse ponto é a senadora Heloísa Helena (PT / AL), que em 2004 sai do PT para entrar no PSOL.

Por fim, na 53a legislatura (Figura 7), o conflito entre os partidos que apoiavam o governo e aqueles que se opunham a ele se mostrou mais forte. Os partidos que estavam no governo deram o seu apoio, com algumas deserções no PMDB - Jarbas Vasconcelos (PMDB/PE) e Mão Santa (PMDB / PI). Ao passo que PFL > DEM e PSDB fizeram uma oposição sistemática.

Algumas conclusões podem ser tiradas a partir dessas figuras. Em primeiro lugar, ao contrário do que sugeria parte da literatura (Ames, 2003; Lamounier, 1994; Mainwaring, 2001), que via os partidos brasileiros como pouco coesos e indisciplinados, vimos que eles se comportam de maneira extremamente previsível, seja na Câmara, seja no Senado. Tais resultados estão em consonância com análises agregadas ao nível do partido (Arretche, 2010; Figueiredo, Limongi, 1999; Neiva, 2011a; 2011b; Santos, 2003). Porém, a vantagem desta pesquisa é que temos não só a posição dos partidos no agregado, mas de cada parlamentar individualmente.

\section{Figura 7}

Optimal Classification - 53 ${ }^{\mathrm{a}}$ Legislatura (2007-2010)

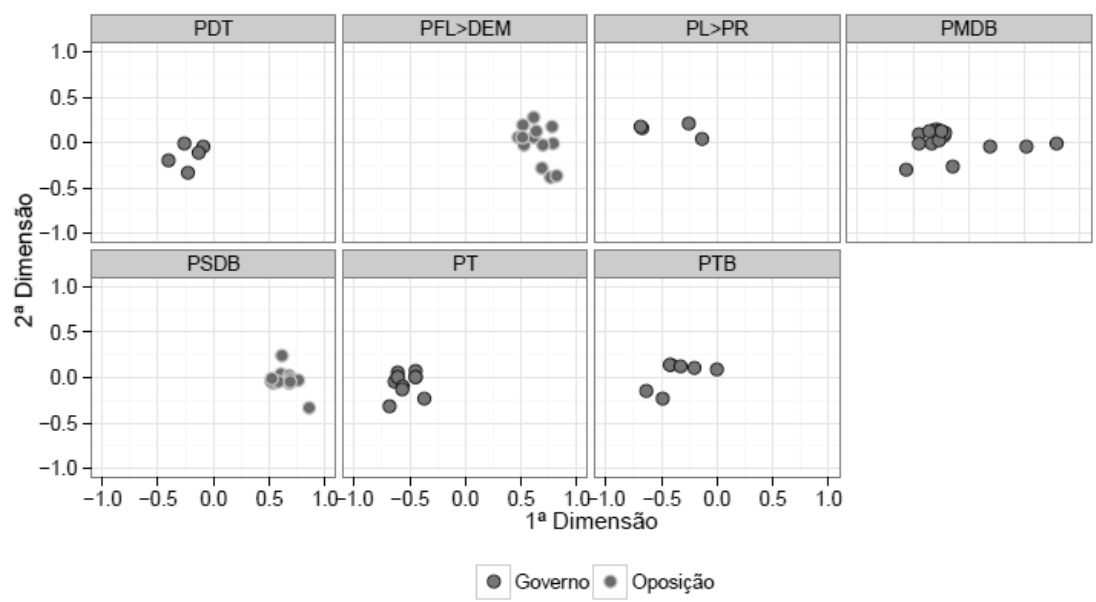

Fonte: Banco de dados legislativos (Cebrap). 
Também é interessante notar que, nos anos recentes, a divisão entre os parlamentares de partidos do governo e parlamentares de partidos da oposição passou a aumentar. Esse fenômeno fica evidente na última legislatura analisada, na qual quase todos os governistas estão à esquerda e os oposicionistas à direita, deixando o centro da escala esvaziado. Ou seja, a crescente polarização no interior do Congresso é um indício da estabilização do sistema político brasileiro que vem ocorrendo, sobretudo, a partir do governo Fernando Henrique.

Na Figura 8 fazemos uma correlação entre as estimativas da 1a dimensão do OC e a porcentagem de votos favoráveis ao governo ${ }^{11}$. Como é possível observar, em quase todas as legislaturas há uma forte correlação entre as duas variáveis. Apenas na 49á é que encontramos uma correlação um pouco mais fraca. Até a 51aㅡ, quanto maior o valor das estimativas da 1믈 dimensão geradas pelo OC, maior a quantidade de votos dados ao governo. A partir da 52로 legislatura, o quadro se inverte. Com a ascensão de um presidente de esquerda, as correlações continuam fortes, mas agora com o sinal negativo. Isso sugere que essa primeira dimensão de fato representa uma clivagem entre governo versus oposição e não as preferências ideológicas dos parlamentares.

Figura 8

Correlação entre a $1^{\mathrm{a}}$ Dimensão (OC) e a Porcentagem de Votos Dados ao Governo

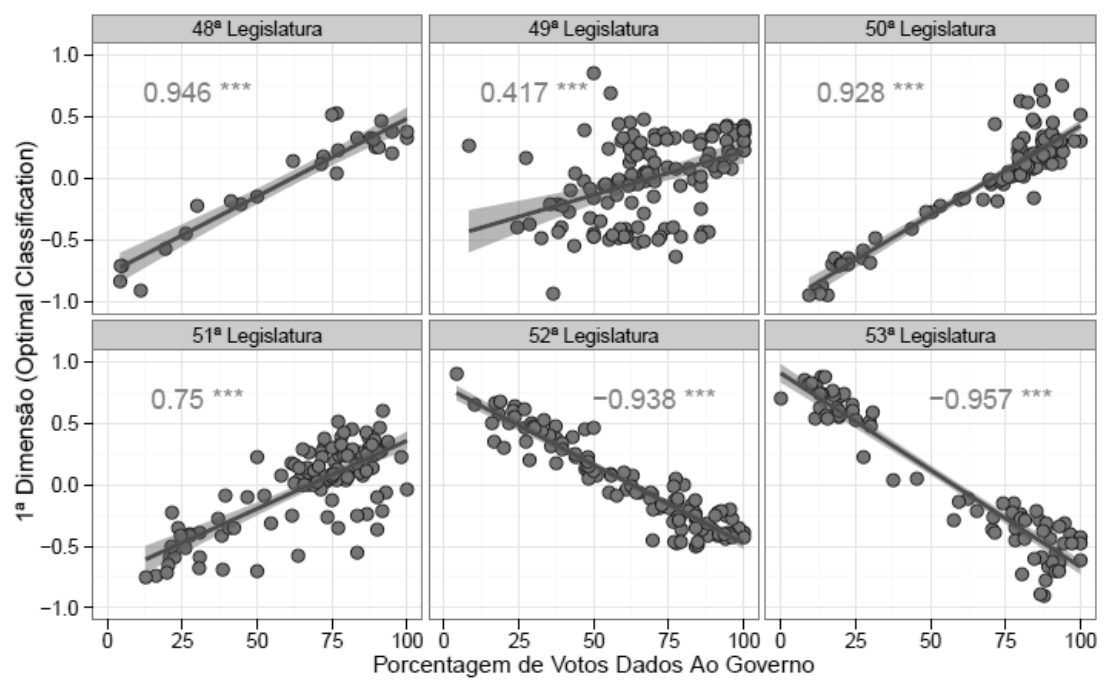

Fonte: Banco de dados legislativos (Cebrap).

DADOS - Revista de Ciências Sociais, Rio de Janeiro, vol. 59, nº 1, 2016 
No entanto, se as coalizões formadas são ideologicamente coerentes, pode parecer difícil distinguir o que é ideologia do que é coalizão pois as duas coisas são colineares. Um teste possível para a hipótese ideológica é olhar para a correlação das estimativas da 1a dimensão do OC entre as legislaturas. Se as correlações forem altas, isso sugere que as posições dos parlamentares são estáveis ao longo do tempo. Caso contrário, se as correlações forem baixas, é um sinal de que as posições dos parlamentares oscilam conforme a mudança de governo. Assim, se estivermos diante de ideologia, o esperado é que as correlações sejam altas.

A Figura 9 apresenta esse teste. Em geral, os valores encontrados não são estatisticamente significantes ao nível de $10 \%$. Ou seja, parecem não sustentar a hipótese ideológica. Olhando para a correlação entre os pares de legislaturas subsequentes temos os seguintes resultados. A correlação entre a 48a e 49å legislaturas é baixa, embora estatisticamente significante. Esse valor baixo não é absurdo, pois durante esse período tivemos três presidentes diferentes (Sarney, Collor e Itamar). Entre as legislaturas 49 e 50 temos um valor de 0,546 . Não podemos dizer que seja baixo. Porém, se olharmos para as coalizões formadas durante o governo de Itamar e de Fernando Henrique, vemos que elas não são tão diferentes. Ambas são sustentadas sobretudo pelo PFL, PMDB e

Figura 9

Correlação entre as Legislaturas

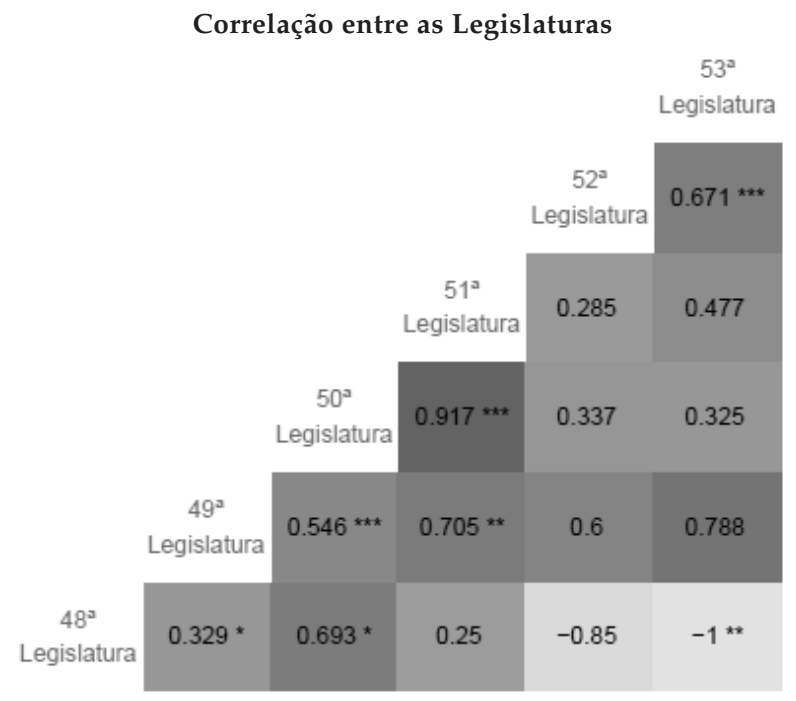

Fonte: Banco de dados legislativos (Cebrap). 
PSDB. A correlação entre a 50a e 51a possui um dos valores mais altos $(0,917)$. Essas são as duas legislaturas sob a presidência de Fernando Henrique que também possuem coalizões muito semelhantes. Entre as legislaturas 51 e 52 temos um valor baixo. Ou seja, com a mudança presidencial e a formação de coalizões razoavelmente distintas, os parlamentares mudaram as suas posições. Por fim, no par 52 e 53, as duas legislaturas sob o governo Lula, temos uma correlação de 0,671. Nas demais combinações, temos, em geral, valores que não são estatisticamente significantes. Isso quer dizer que os parlamentares não possuem posições estáveis ao longo do tempo. Fato que contraria a ideia de ideologia.

Esse resultado não é anormal. Spirling e McLean (2007) apresentam conclusões semelhantes para a U.K. House of Commons. De acordo com os autores, a natureza do governo versus oposição do modelo Westminster britânico faz com que as estimativas geradas pelo Optimal Classification não possam ser interpretadas como um continuum ideológico. Como argumenta Clinton (2012:95), pontos ideais estimados a partir de votações nominais não são necessariamente medidas das verdadeiras preferências dos parlamentares. Eles são somente um conjunto de pontos que racionalizam o comportamento revelado dos parlamentares dado os pressupostos de um modelo.

Em resumo, o que vimos até aqui foi que, com uma única dimensão, somos capazes de representar razoavelmente bem as preferências manifestas em votações nominais dos senadores brasileiros. Vimos também que essa dimensão reflete o conflito entre governo e oposição. E mais, esse resultado não é singular. O mesmo ocorre em diversas legislaturas ao redor do mundo. A questão agora é saber o que explica esse padrão. Esse é o tópico da próxima seção.

\section{GOVERNO E OPOSIÇÃO?}

Será que entrar ou sair da coalizão de governo faz diferença? Em outras palavras, será que entrar/sair da coalizão modifica o comportamento dos senadores? Ou será que eles mantêm a mesma posição durante toda a legislatura independentemente da entrada ou saída de seu partido na coalizão governamental? Em suma, fazer parte da coalizão de governo é a causa desse comportamento?

Essas questões não são triviais. Como lembra Krehbiel (1993; 2000), o simples fato de haver uma homogeneidade de preferências no interior 
de um partido e diversidade entre os partidos não leva necessariamente à conclusão de que o comportamento dos parlamentares seja tido como partidário. Dito de forma direta, uma coisa é dizer que temos uma medida de partidarismo, outra é dizer que o partido é uma causa significante e independente do comportamento partidário.

Por exemplo, suponhamos que o resultado de todas as votações nominais fosse determinado por lançamentos de moedas. Suponhamos também que esse teste gerasse uma medida partidária tal qual do parlamento britânico. Em um cenário improvável como este, seria razoável questionar se o rótulo "partidário" seria digno desse nome. É preciso considerar formas alternativas de comportamentos que poderiam ter gerado medidas similares de partidarismo (Krehbiel, 2000:213).

Para o caso aqui analisado, verificamos uma alta correlação entre as estimativas geradas pelo Optimal Classification e a proporção de votos favoráveis dados ao governo. Ou seja, temos uma medida que expressa o conflito entre governo e oposição. No entanto, o ponto para o qual estamos chamando a atenção é que isso não nos leva à conclusão de que o fato de um parlamentar pertencer -ou não - à coalizão formal do governo seja a causa desse comportamento.

Para verificar se estar ou não na coalizão de governo faz diferença iremos comparar as estimativas geradas pelo OC dos indivíduos que estiveram no governo com as estimativas geradas para os mesmos indivíduos quando foram para a oposição (ou vice-versa). Como argumenta Nokken (2000:421), mudanças partidárias são um fenômeno importante, pois nos permitem avaliar a importância do partido sobre o comportamento em votações nominais como um todo. O conjunto de indivíduos que mudaram de status serve como um grupo para testar como mudanças de filiações partidárias podem influenciar no comportamento legislativo. Comparar o padrão de votações nos momentos pré e pós-mudança nos permite tirar conclusões não apenas sobre esses indivíduos, mas também sobre a importância dos partidos políticos em modelar o comportamento de todos os parlamentares. Em nosso caso, substitua partidos políticos por coalizão governamental. Ou seja, iremos comparar os parlamentares que estiveram tanto no governo como na oposição com o objetivo de aferir a importância da coalizão no comportamento em votações nominais.

Neste ponto, o procedimento que iremos seguir é semelhante ao que Kousser, Lewis e Masket (2007) implementaram para estudar a mu- 
dança de comportamento dos congressistas da assembleia do estado da Califórnia após a substituição do governador democrata Gray Davis pelo republicano Arnold Schwarzenegger. Nesse evento, não apenas a maioria dos eleitores da Califórnia, mas também uma maioria em 18 dos 48 distritos controlados pelos democratas, votaram a favor do candidato republicano. Como mostram os autores, após esse evento, os parlamentares democratas caminharam em direção ao centro do espectro ideológico, moderando as suas posições com vistas a sobreviver eleitoralmente.

Nosso objetivo, porém, é comparar somente a posição dos senadores que estiveram tanto no governo, quanto na oposição, para avaliar a importância da coalizão de governo no comportamento legislativo. Esse teste se torna possível devido a nossa unidade de análise - senador/coalizão. Pois ao tomar essa decisão duplicamos os senadores que migraram de partidos do governo para partidos da oposição (ou vice-versa); e/ou parlamentares de partidos que entraram/saíram da coalizão; e mantemos com um único registro todos os outros. Lembremos que a comparação é possível somente se assumirmos que o comportamento dos parlamentares com um único registro não é afetado pelas mudanças das coalizões. Por exemplo, na 50a legislatura, quando o PP entra para a coalizão de governo, assumimos que o comportamento dos parlamentares do PFL (partido que esteve sempre na coalizão) não foi afetado por esse evento. Esse pressuposto é importante para podermos colocar na mesma escala os registros dos parlamentares que votaram somente antes (quando eram oposição, no caso do PP) e somente depois (governo) [Kousser, Lewis e Masket, 2007:835].

Na Tabela 4 apresentamos o número de senadores duplicados e únicos. Nas quatro legislaturas em que esse teste foi possível tivemos em média $26,9 \%$ de senadores duplicados e 73,1\% de senadores únicos.

Tabela 4

Senadores Duplicados e Senadores Únicos

\begin{tabular}{l|c|c|c}
\hline Legislatura & Senadores Duplicados & Senadores Únicos & Total \\
\hline $49^{\underline{a}}$ & $40(43,5 \%)$ & $52(56,5 \%)$ & 92 \\
$50^{\underline{a}}$ & $12(13,5 \%)$ & $77(86,5 \%)$ & 89 \\
$51^{\underline{a}}$ & $20(21,5 \%)$ & $73(78,5 \%)$ & 93 \\
$52^{\underline{a}}$ & $24(29,0 \%)$ & $59(71,0 \%)$ & 83 \\
\hline
\end{tabular}

Fonte: Banco de dados legislativos (Cebrap). 


\section{Mauricio Yoshida Izumi}

Na Figura 10 temos os pontos ideais dos senadores duplicados. Em cada linha temos a posição do parlamentar como governista (círculo) e como oposicionista (triângulo). À primeira vista parece um pouco difícil saber se há diferença entre as estimativas dos parlamentares quando estavam no governo (ou na oposição) e dos mesmos quando na oposição (ou no governo). Alguns parlamentares possuem pontos ideais visualmente muito distantes na pré e na pós-entrada/saída da

Figura 10

Governo e Oposição

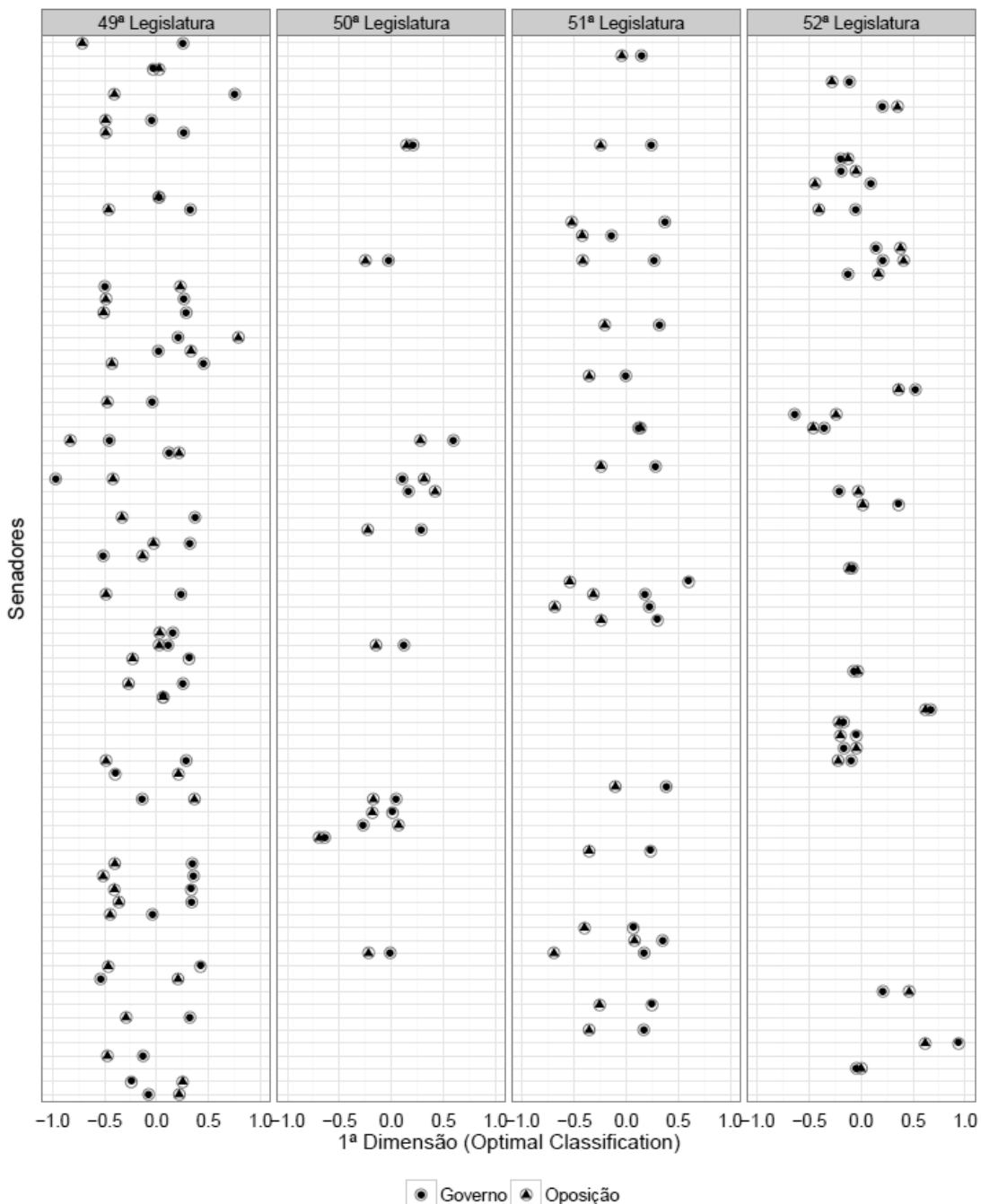

Fonte: Banco de dados legislativos (Cebrap). 
coalizão. Outros, porém, possuem pontos muito próximos. O que equivale a dizer que não há muita diferença entre as estimativas dos parlamentares quando estavam no governo (ou na oposição) e dos mesmos quando na oposição (ou no governo). Ou seja, parece que alguns senadores que eram da oposição e foram para o governo já apoiavam a agenda governamental e os senadores que fizeram o caminho inversoforam do governo para a oposição - continuaram a dar seus votos para o governo.

$\mathrm{Na}$ 49a legislatura, vemos claramente que alguns senadores mudaram de posição após a entrada/saída da coalizão de governo. No entanto, é importante não perder de vista que nessa legislatura tivemos cinco coalizões e dois presidentes. A questão de ter dois presidentes, sobretudo, como já argumentamos, parece afetar os resultados, pois as mudanças mais significativas de comportamento são de parlamentares ${ }^{12}$ do PSDB e do PMDB - partidos que entraram para a coalizão apenas no governo de Itamar Franco.

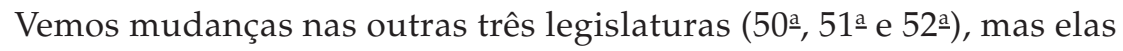
não parecem ser muito grandes para alguns senadores. Na 52a legislatura, por exemplo, muitos deles têm os seus pontos ideais como governistas e como oposicionistas sobrepostos.

Para termos uma visão mais geral desse fenômeno é interessante olharmos para a média das diferenças. Dito de forma análoga, iremos computar a diferença entre o ponto ideal de cada parlamentar quando estava no governo e na oposição e fazer a média aritmética da legislatura. Fazendo isso temos os seguintes valores: 0,52 para a 49a legislatura;

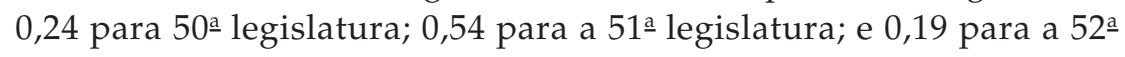
legislatura. Não é demais lembrar que os valores possíveis estão no intervalo $[0,2]$.

Ainda seguindo Kousser, Lewis e Masket (2007), com vistas a determinar a significância estatística desses valores (média das diferenças), fizemos algumas simulações. Construímos para cada legislatura 1.000 bancos de dados nos quais randomizamos as posições dos parlamentares duplicados. Para ser mais claro, vamos supor que um senador qualquer tenha votado as 100 primeiras votações como governo e as 50 últimas como oposição. Ao randomizarmos a sua posição, o que estamos fazendo é transformar algumas das 100 primeiras votações como governista em oposicionista e algumas das 50 últimas como governista em oposicionista. A ideia é saber se a diferença encontrada não é fruto 
do acaso. Por exemplo, o senador Álvaro Dias migrou do governo para a oposição em 25 de setembro de 2001. Assim, na matriz original, todas as votações de que ele participou como governista ocorreram entre o início da 51ํㅡ legislatura e o dia da mudança, e dessa data até o final da legislatura ele votou como oposicionista. Quando randomizamos a sua posição, temos que os votos que ele deu como governista e como oposicionista estarão juntos nos seus dois registros. Ao fazermos isso várias vezes (1.000 vezes), temos uma distribuição para comparar com a diferença média encontrada na matriz original. Caso a média encontrada na matriz original seja um valor frequente na distribuição dos valores simulados, não rejeitamos a hipótese nula de que não há diferença de comportamento com a entrada ou saída da coalizão de governo. Caso contrário, se a magnitude da média das diferenças for muito maior do que as da distribuição, rejeitamos a hipótese nula de que não há mudança de comportamento.

Na Figura 11, a distribuição representada pela linha consecutiva é referente à média das diferenças de cada uma das 1.000 simulações, e a linha tracejada é a média das diferenças original. Como vemos, em todas as legislaturas as médias originais são significativamente maiores do que as das distribuições. Na 50a e na 52a legislaturas, as diferenças não são tão grandes. Mesmo assim, elas ainda são maiores do que a maior parte dos valores simulados. Indo direto ao ponto, rejeitamos a hipótese nula segundo a qual entrar ou sair da coalizão de governo não faz diferença no comportamento em votações nominais dos senadores brasileiros.

Os resultados aqui apresentados são alguns indícios da importância da coalizão de governo na modelagem do comportamento legislativo.

Figura 11

Média das Diferenças

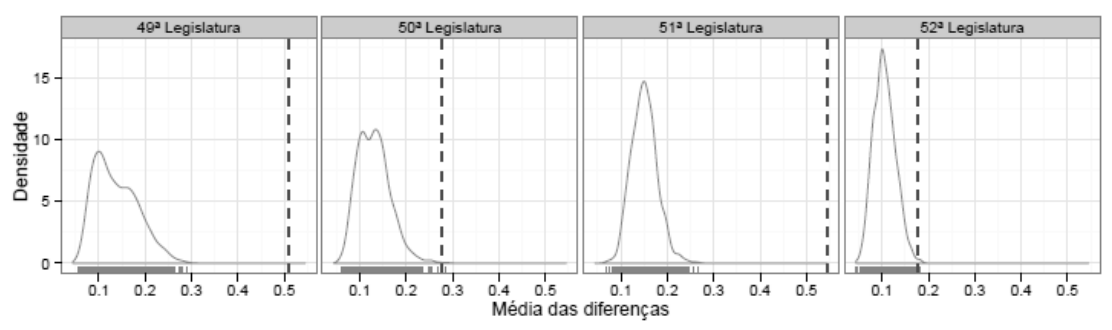

Fonte: Banco de dados legislativos (Cebrap). 
Ao que parece, senadores que estavam no governo e migraram para partidos de oposição mudaram significativamente os seus padrões de votações. Ou seja, esse grupo de parlamentares passou a apoiar mais a agenda governamental após a entrada na coalizão.

Outra forma de abordar essa questão é olhar para a segunda dimensão. O raciocínio é o seguinte: se for possível classificar, em cada uma das votações, os parlamentares em uma escala que vai de um extremo governista a um extremo oposicionista, então seguramente estaríamos diante de um espaço unidimensional caracterizado pelo conflito entre governo e oposição. No entanto, se a classificação for dependente da temática que está sendo votada, então é provável que outras dimensões sejam relevantes (Crespin e Rohde, 2010:977).

Na Figura 12, classificamos as votações a partir de diversas áreas temáticas ${ }^{13}$ e calculamos a frequência das votações selecionadas como bem explicadas pela segunda dimensão - ou seja, aquelas em que PRE2 PRE1 $=0,2$, ou dito em palavras, em que a diferença entre o PRE com duas dimensões e o PRE com uma dimensão é maior ou igual a 0,2 (Poole e Rosenthal, 2007:57). Do ponto de vista substantivo, uma votação é considerada bem explicada pela segunda dimensão quando os parlamentares se comportaram de um modo diferente daquele previsto pelo modelo com uma única dimensão.

Em primeiro lugar, o que podemos ver por essa figura é que, em algumas legislaturas, as votações se distribuíram em poucas áreas temáticas. Por exemplo, na $48^{\mathrm{a}}$ legislatura foram votados nominalmente apenas projetos que diziam respeito ao processo legislativo, direito eleitoral e partidos políticos e comunicações. Isso, no entanto, não quer dizer que durante esse período não tenha se legislado sobre outros temas, como saúde e educação. Lembremos, nem tudo é votado nominalmente.

Vemos também que, em geral, não há uma temática predominante sendo acionada. Quer dizer, há um número baixo de votações selecionadas em relação ao total de votações em cada tema. Isso nos indica que as votações que são mais bem adequadas pela segunda dimensão não seguem um padrão por assunto. Assim, não podemos afirmar qual o seu conteúdo. A única coisa que sabemos é que ela acrescenta muito pouco na explicação. 


\section{Mauricio Yoshida Izumi}

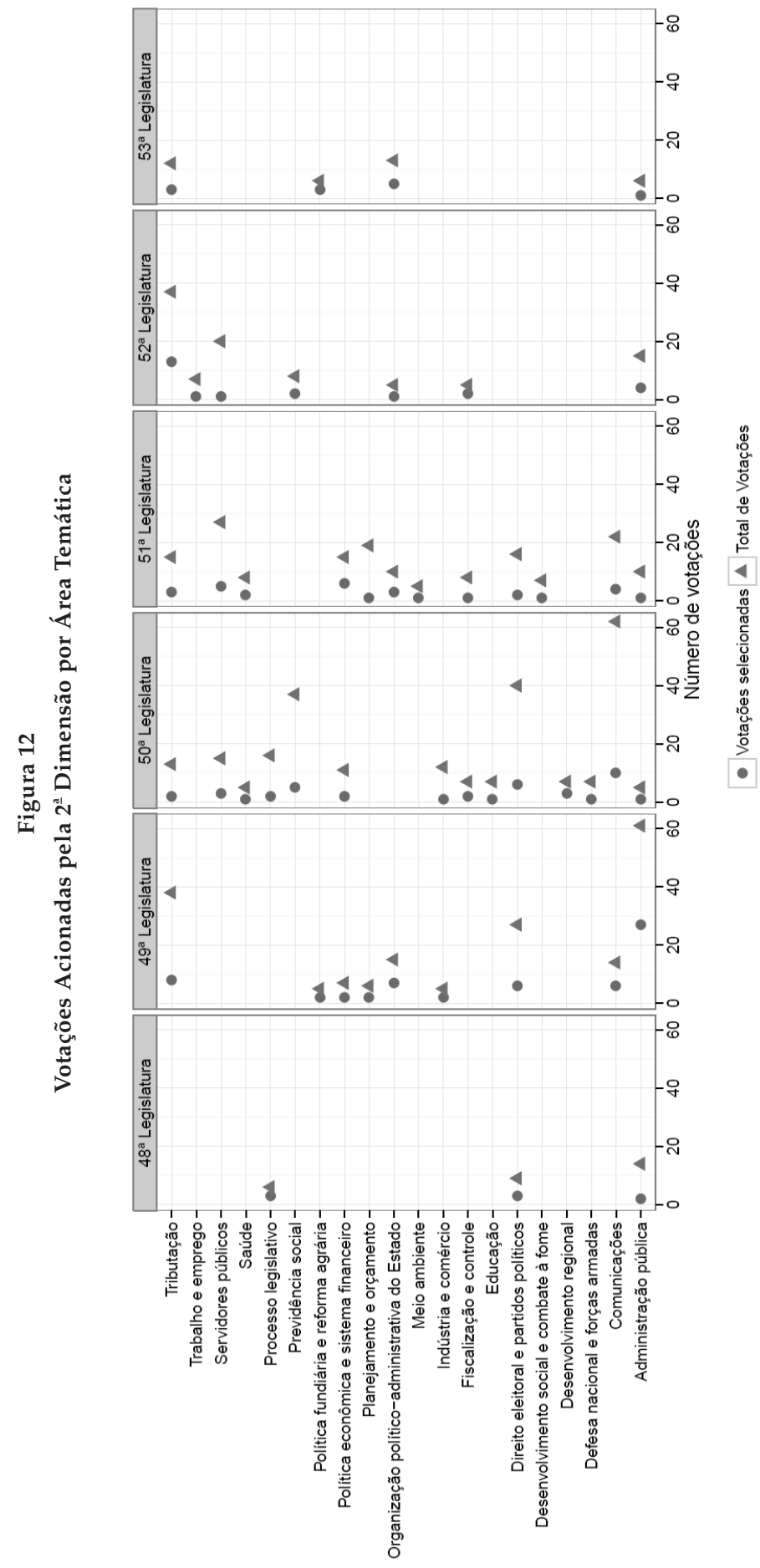

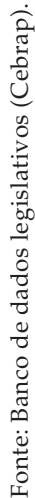

124 DADOS - Revista de Ciências Sociais, Rio de Janeiro, vol. 59, noำ 1, 2016 
Contudo, mais interessante do que isso é olhar para o resultado final dessas votações. A partir do voto do líder do governo podemos classificar de forma rudimentar cada uma das votações como uma vitória ou derrota do governo. Se o voto do líder estiver em acordo com o resultado vitorioso, diremos que o governo obteve uma vitória. Caso contrário, o governo foi derrotado. A Tabela 5 apresenta o resultado desse teste.

Nela cruzamos o resultado das votações (vitória ou derrota do governo) com a variável que indica se a votação foi (PRE2 - PRE1 = 0,2) ou não (PRE2 - PRE1 <0,2) acionada pela segunda dimensão. O que é relevante reparar é que as proporções de derrotas e de vitórias são semelhantes nos dois grupos de votações. Isso quer dizer que mesmo nas votações que não são tão bem explicadas pelo modelo unidimensional o governo venceu na mesma proporção que no outro conjunto de votações bem explicadas. E, em alguns momentos (49a , 52a e e 53a legislaturas), a proporção de vitórias chegou até a ser maior nas votações em que a segunda dimensão surgiu como relevante. Em suma, não há diferença significativa entre os dois grupos de votações. Em ambas o governo obteve um número alto de vitórias.

Para uma visão mais precisa podemos olhar para o resultado do teste de independência qui-quadrado $\left(\chi^{2}\right)$. Como somos capazes de constatar, os valores de p não são baixos. Com exceção da 49ª legislatura (valor-p $=0,037$ ), todos são maiores do que 0,25 . Desse modo, não podemos rejeitar a hipótese nula de independência entre os eventos ao nível de significância de 5\%. Outra alternativa é olhar para o coeficiente de contingência. Como, a princípio, o $\chi^{2}$ pode assumir valores muito grandes e não está limitado a um intervalo [0,1], o coeficiente de contingência é uma alternativa por ser de mais fácil interpretação. Pela Tabela 5 vemos que ele é baixo em todas as legislaturas. Novamente, com exceção da 49å legislatura $(0,371)$, os valores não passam de 0,15 .

Em síntese, nesta seção procuramos explorar o papel da coalizão de governo na estruturação do comportamento dos senadores brasileiros. Vimos que ao entrar/sair dela, em geral, os parlamentares tendem a mudar de comportamento. Isto é, se estavam na oposição, passaram a apoiar o governo. Se estavam no governo, passaram a fazer oposição. E esse tipo de comportamento é constante seja lá qual for o tema em votação. Quer dizer, não há uma área temática em específico que seja sistematicamente acionada por uma segunda dimensão. 


\section{Mauricio Yoshida Izumi}

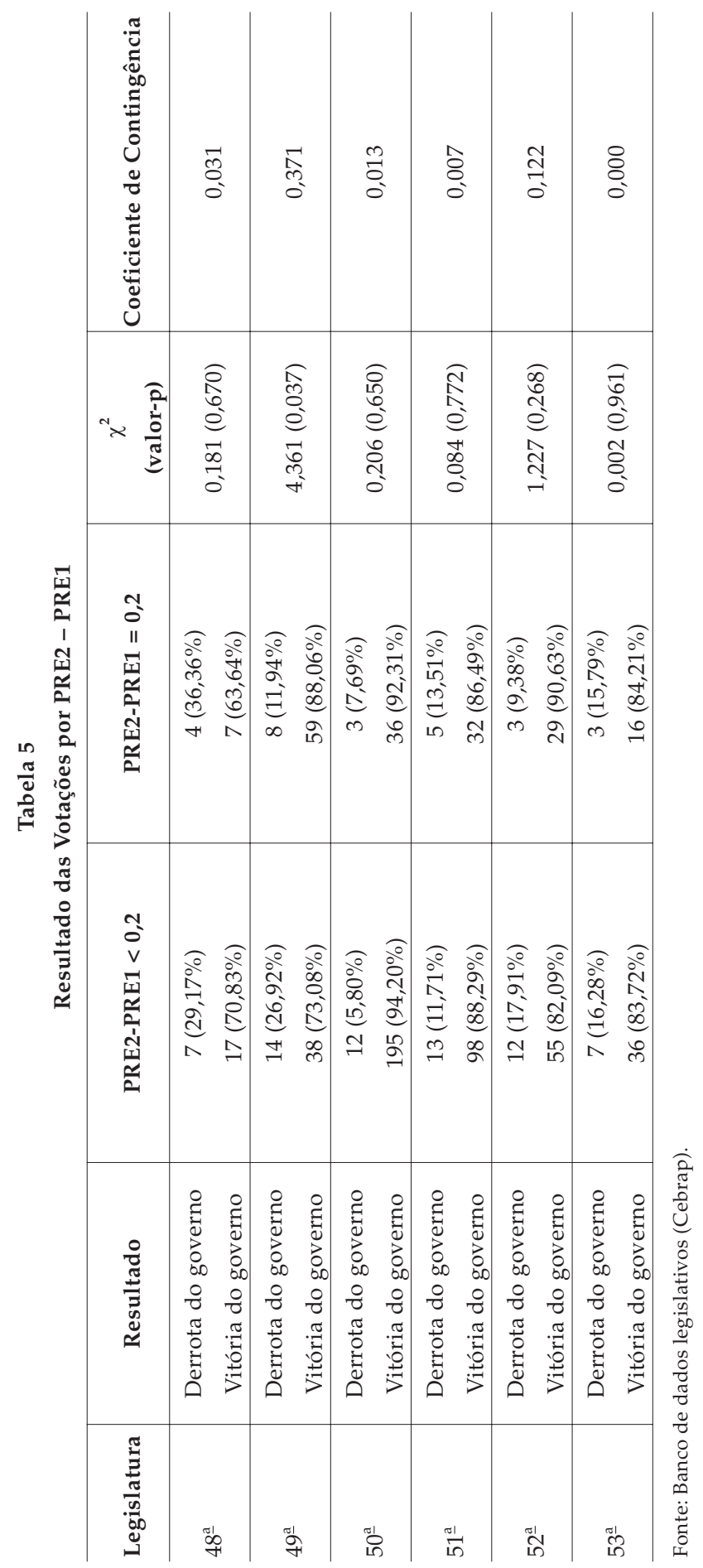

126 DADOS - Revista de Ciências Sociais, Rio de Janeiro, vol. 59, no 1, 2016 
E mesmo que possamos atribuir um conteúdo substantivo a ela, o ponto é que o governo continua vencendo na mesma proporção que nas votações que são puramente de uma dimensão. Isso quer dizer que, se somos informados que uma votação foi acionada pela segunda dimensão, ou seja, que os parlamentares se comportaram de uma forma não prevista pelo modelo unidimensional, isso não altera a nossa crença sobre o governo ter vencido ou não essa votação. A probabilidade de ele ter vencido ainda é maior.

\section{CONSIDERAÇÕES FINAIS}

Este artigo chegou a duas conclusões principais, uma de ordem metodológica e outra de ordem substantiva. Do ponto de vista metodológico, procuramos argumentar a favor do uso da técnica de estimação de pontos ideais não paramétrica Optimal Classification (Poole, 2000). Essa escolha parece ser adequada para o caso brasileiro, visto que o OC não é sustentado sobre qualquer pressuposto da forma funcional das preferências dos parlamentares e sobre a distribuição dos erros. Ele assume somente que as preferências são simétricas e de pico único e que o espaço político é euclidiano. Técnicas paramétricas, como o W-Nominate e o IDEAL, por outro lado, assumem que os erros são independentes e identicamente distribuídos entre os legisladores e entre as votações. Tal especificação parece não ser adequada para o caso brasileiro, no qual a disciplina partidária varia entre os partidos e a migração não é um fenômeno raro. Isto é, um ambiente em que a variância do erro não é homocedástica.

Com relação à conclusão de ordem substantiva, a principal questão a ser respondida foi quantas e quais dimensões são necessárias para representar razoavelmente bem as preferências dos senadores brasileiros. Como foi visto, uma única dimensão que expressa o conflito entre governo e oposição é suficiente. Esses achados vão contra as inferências feitas por parte da literatura (Ames, 2003; Lamounier, 1994; Mainwaring, 2001), seja por preverem um caos no interior do Congresso, seja por preverem a existência de coalizões federativas de veto. Mas estão em consonância com outras análises agregadas ao nível do partido (Arretche, 2010; Figueiredo e Limongi, 1999; Neiva, 2011a; 2011b; Santos, 2003). Porém, nossa proposta tem a vantagem de ter estimativas desagregadas ao nível do indivíduo, o que nos permitiu aferir de forma mais acurada o papel da coalizão de governo no comportamento legislativo. 
Sugerimos finalmente que parte significativa desse comportamento é fruto da lógica que conduz o processo de formação de coalizões no Brasil. Isto é, o padrão encontrado é resultado em grande medida das estratégias adotadas pelos partidos políticos. Assim, o apoio ao governo se dá por meio da construção de coalizões.

(Recebido para publicação em novembro de 2013)

(Reapresentado em novembro de 2014)

(Aprovado para publicação em maio de 2015) 


\section{Governo e Oposição no Senado Brasileiro (1989-2010)}

\section{NOTAS}

1. O indicador de estabilidade constitucional é o número de emendas constitucionais feitas por ano.

2. Para mais, ver Ames (2002), Carrubba et al. (2009), Carrubba, Gabel, Hug (2008) e Hug (2010).

3. O único pressuposto é o de que as preferências dos legisladores são simétricas e de pico único e as decisões são tomadas em um espaço euclidiano.

4. Segundo Poole e Rosenthal (1985:367), este é um bom valor para equilibrar a qualidade das coordenadas dos legisladores e a qualidade das coordenadas das votações. Além disso, este é o valor padrão que tem sido utilizado nos estudos que se propuseram a aplicar técnicas de estimação de pontos ideais.

5. De acordo com Nokken e Poole (2004:550), entre 1793 e 2000 ocorreram 38 migrações partidárias no Senado e 160 na Câmara americana. Segundo Freitas (2012:956), na Câmara dos Deputados brasileira entre 1987 e 2009 ocorreram 1.407 migrações. Para

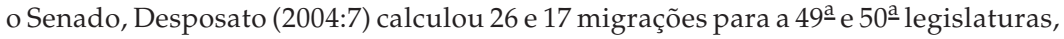
respectivamente.

6. A primeira formulação foi de Hotelling (1929), com aplicações na economia. Posteriormente, Downs (1957) o utilizou para estudar a competição eleitoral.

7. Além da unidimensionalidade, esse modelo assume que as preferências são de pico-único e que o voto é sincero.

8. O cálculo da APRE é dado pela seguinte expressão (Poole, 2005:129):

APRE $=\frac{\sum_{j=1}^{q}(\text { Votos da Minoria }- \text { Erros feitos pelo OC }) j}{\sum_{j=1}^{q}(\text { Votos da Minoria }) j}$, onde $j=1, \ldots$, q é o número de votações.

9. A segunda dimensão se mostrou mais relevante durante dois períodos em que as questões raciais se tornaram centrais para a política norte-americana. O primeiro foi durante os debates sobre a escravidão entre as décadas de 1830 e 1850. E o segundo durante as controvérsias relativas aos direitos civis entre as décadas de 1940 e 1960 (Poole e Rosenthal, 2007:4).

10. Serão analisados apenas os partidos que tiveram ao menos três senadores estimados pelo OC na respectiva legislatura.

11. A porcentagem de votos favoráveis ao governo nada mais é do que a porcentagem de vezes em que um parlamentar acompanhou o voto do líder do governo. Para fazer esse cálculo foram excluídas as votações em que $90 \%$ do plenário votou da mesma forma.

12. Alguns exemplos são Mário Covas (SP), Chagas Rodrigues (PI), Beni Veras (CE) e Dirceu Carneiro (SC) do PSDB e José Fogaça (RS), Pedro Simon (RS), Ronaldo Aragão (RO), Mansueto de Lavor (PE) e Garibaldi Alves (RN) do PMDB.

13. Na página do Senado Federal na internet (www.senado.gov.br) existe uma classificação por assunto dos projetos propostos a partir de 1999. Para as votações de nossa base de dados relativas a esses projetos utilizamos essa classificação. Para as votações anteriores a 1999, estendemos, na medida do possível, os mesmos critérios. 


\section{Mauricio Yoshida Izumi}

\section{REFERÊNCIAS BIBLIOGRÁFICAS}

ABRANCHES, Sérgio. (1988), "Presidencialismo de Coalizão: O Dilema Institucional Brasileiro". DADOS - Revista de Ciências Sociais, vol. 31, no 1, pp. 5-38.

ABRÚCIO, Fernando. (1998), Os Barões da Federação: Os Governadores e a Redemocratização Brasileira. São Paulo, Hucitec.

ALEMÁN, Eduardo. (2008), "Policy Positions in the Chilean Senate: An Analysis of Coauthorship and Roll Call Data". Brazilian Political Science Review (Online), vol. 3, no se, pp. 74-92.

; SAIEGH, Sebastián. (2007), “Legislative Preferences, Political Parties, and Coalition Unity in Chile. Comparative Politics, vol. 39, no 3, pp. 253-272.

ALTMAN, David. (2000), "The Politics of Coalition Formation and Survival in Multiparty Presidential Democracies: The Case of Uruguay, 1989-1999". Party Politics, vol. 6, no 3, pp. 259-283.

AMES, Barry. (2002), "Party Discipline in the Chamber of Deputies", in S. Morgenstern; B. Nacif (orgs.), Legislative Politics in Latin America. Cambridge, Cambridge University Press.

(2003), Os Entraves da Democracia no Brasil. Rio de Janeiro, FGV Editora.

AMORIM NETO, Octavio. (2000), “Gabinetes Presidenciais, Ciclos Eleitorais e Disciplina Legislativa no Brasil". DADOS - Revista de Ciências Sociais, vol. 43, no 3, pp. 479-519.

; SANTOS, Fabiano. (2001), “A Conexão Presidencial: Facções pró e Antigoverno e Disciplina Partidária no Brasil”. DADOS - Revista de Ciências Sociais, vol. 44, no 2, pp. 291-321.

ARRETCHE, Marta. (2007), “The Veto Power of Sub-National Governments in Brazil: Political Institutions and Parliamentary Behaviour in the Post-1988 Period". Brazilian Political Science Review (Online), vol. 2, no se, pp. 40-73.

(2010), “Federalism, Bicameralism, and Institutional Change: General Trends and One Case-Study". Brazilian Political Science Review (Online), vol. 5, no se, pp. 10-31.

BAILEY, Michael. (2007), “Comparable Preference Estimates Across Time and Institutions for the Court, Congress, and Presidency". American Journal of Political Science, vol. 51, no 3, pp. 433-448.

BLACK, Duncan. (1958), The Theory of Committees and Elections. Cambridge, Cambridge University Press.

CARROLL, Royce et al. (2013), "The Structure of Utility in spatial Models of Voting". American Journal of Political Science, vol. 57, no 4, pp. 1008-1028.

CARRUBBA, Clifford; GABEL, Matthew; HUG, Simon. (2008), "Legislative Voting Behavior, Seen and Unseen: A Theory of Roll-Call Vote Selection". Legislative Studies Quarterly, vol. 33, no 4, pp. 543-572.

CARRUBA, Clifford et al. (2006), "Off the Record: Unrecorded Legislative Votes, Selection Bias and Roll-Call Vote Analysis". British Journal of Political Science, vol. 36, no 4, pp. 691-704. 
CHEIBUB, José; FIGUEIREDO, Argelina; LIMONGI, Fernando. (2009), “Partidos Políticos e Governadores como Determinantes do Comportamento Legislativo na Câmara dos Deputados, 1988-2006". DADOS - Revista de Ciências Sociais, vol. 52, no 2, pp. 263-299.

CLINTON, Joshua. (2012), “Using Roll Call Estimates to Test Models of Politics”. Annual Review of Political Science, vol. 15, pp. 79-99.

; JACKMAN, Simon; RIVERS, Douglas. (2004), “The Statistical Analysis of Roll Call Data". American Political Science Review, vol. 98, no 2, pp. 355-370.

CRESPIN, Michael; ROHDE, David. (2010), “Dimensions, Issues, and Bills: Appropriations Voting on the House Floor". The Journal of Politics, vol. 72, no 4, pp. 976-989.

DESPOSATO, Scott. (2004), The Impact of Party-Switching on Legislative Behavior in Brazil. Mimeo.

(2005), “Parties for Rent? Ambition, Ideology, and Party Switching in Brazil's Chamber of Deputies". American Journal of Political Science, vol. 50, no 1, pp. 62-80.

. (2006), "The Impact of Electoral Rules on Legislative Parties: Lessons from the Brazilian Senate and Chamber of Deputies". Journal of Politics, vol. 68, no 4, pp. 1018-1030.

DOWNS, Anthony. (1957), An Economic Theory of Democracy. New York, Harper \& Row.

ENELOW, James; HINICH, Melvin. (1984), The Spatial Theory of Voting: An Introduction. Cambridge, Cambridge University Press.

FIGUEIREDO, Argelina. (2011), "Government Coalitions in Brazilian Democracy". Brazilian Political Science Review (Online), vol.1, no 2, pp. 182-216.

; LIMONGI, Fernando. (1999), Executivo e Legislativo na Nova Ordem Constitucional. Rio de Janeiro, FGV Editora.

. (2000), "Presidential Power, Legislative Organization, and Party Behavior in Brazil". Comparative Politics, vol. 32, no 2, pp. 151-170.

FREITAS, Andréa. (2012), “Migração Partidária na Câmara dos Deputados de 1987 a 2009". DADOS - Revista de Ciências Sociais, vol. 55, no 4, pp. 951-986.

HINICH, Melvin; MUNGER, Michael. (1997), Analytical Politics. Cambridge, Cambridge University Press.

HIX, Simone; JUN, Hae-Won. (2009), "Party Behaviour in the Parliamentary Arena: The Case of the Korean National Assembly". Party politics, vol. 15, no 6, pp. 667-694.

HOTELLING, Harold. (1929), "Stability in competition”. The Economic Journal, vol. 39, no 153, pp. 41-57.

HUG, Simon. (2010), "Selection Effects in Roll Call Votes". British Journal of Political Science, vol. 40, no 1, pp. 225-235.

JONES, Mark; HWANG, Wonjae. (2005), "Party Government in Presidential Democracies: Extending Cartel Theory beyond the U.S. Congress". American Journal of Political Science, vol. 49, no 2, pp. 267-282.

JONES, Mark; HWANG, Wonjae; MICOZI, Juan. (2008), Government and Opposition in Argentina, 1989-2007: Understanding Inter-Party Dynamics through Roll Call Vote 


\section{Mauricio Yoshida Izumi}

Analysis. Trabalho apresentado no simpósio New Frontiers on Institutional Research in Latin America, German Institute of Global Affairs (GIGA), Hamburgo, 5-6 de maio.

KOUSSER, Thad; LEWIS, Jeffrey; MASKET, Seth. (2007), "Ideological Adaptation? The Survival Instinct of Threatened Legislators". Journal of Politics, vol. 69, no 3, pp. 828-843.

KREHBIEL, Keith. (1993), “Where's the Party?”. British Journal of Political Science, vol. 23, no 2, pp. 235-266.

. (2000), "Party Discipline and Measures of Partisanship". American Journal of Political Science, vol. 44, no 2, pp. 212-227.

LAMOUNIER, Bolívar. (1994), “A Democracia Brasileira de 1985 à Década de 90: A Síndrome da Paralisia Hiperativa”, in J. Velloso (org.), Governabilidade, Sistema Politico e Violência Urbana. Rio de Janeiro, José Olympio, pp. 26-63.

LEONI, Eduardo. (2002), “Ideologia, Democracia e Comportamento Parlamentar: A Câmara dos Deputados (1991-1998)". DADOS - Revista de Ciências Sociais, vol. 45, no 3, pp. 361-386.

LIJPHART, Arendt. (1999), Patterns of Democracy: Government Forms and Performance in Thirty-Six Democracies. New Haven, Yale University Press.

LLANOS, Mariana; NOLTE, Detlef. (2003), “Bicameralism in the Americas: Around the Extremes of Symmetry and Incongruence". The Journal of Legislative Studies, vol. 9, no 3, pp. 54-86.

LLANOS, Mariana; SÁNCHEZ, Francisco. (2006), “Council of Elders? The Senate and its Members in the Southern Cone". Latin American Research Review, vol. 41, no 1, pp. 133-152.

LOUREIRO, Maria. (2001), "O Senado no Brasil Recente: Política e Ajuste Fiscal”. São Paulo em Perspectiva, vol. 15, no 4, pp. 53-61.

MAINWARING, Scott. (2001), Sistemas Partidários em Novas Democracias: O Caso do Brasil. Porto Alegre, Mercado Aberto.

MCCARTY, Nolan. (2011). "Measuring Legislative Preferences”, in E. Schickler; F. Lee (eds.), Oxford Handbook of American Congress. Oxford, Oxford University Press.

; POOLE, Keith; ROSENTHAL, Howard. (2001), “The Hunt for Party Discipline in Congress". American Political Science Review, vol. 95, no 3, pp. 673-688.

MCKELVEY, Richard. (1976), "Intransitivities in Multidimensional Voting Models and Some Implications for Agenda Control". Journal of Economic Theory, vol. 12, no 3, pp. 472-482.

MELO, Carlos. (2004), Retirando as Cadeiras do Lugar: Migração Partidária na Câmara dos Deputados, 1985-2002. Belo Horizonte, UFMG Editora.

MYAGKOV, Mikhail; KIEWIET, D. Roderick. (1996), "Czar Rule in the Russian Congress of People's Deputies?". Legislative Studies Quarterly, vol. 21, no 1, pp. 5-40.

NEIVA, Pedro. (2004), Estudo Comparado de Câmaras Altas: Os Poderes e o Papel dos Senados nos Sistemas Presidencialistas. Tese (Doutorado em Ciência Política), Iuperj, Rio de Janeiro. 
(2006), "Os Determinantes da Existência e dos Poderes das Câmaras Altas: Federalismo ou Presidencialismo?". DADOS - Revista de Ciências Sociais, vol. 49, no 2, pp. 269-299.

. (2011a), “Coesão e Disciplina Partidária no Senado Federal”. DADOS - Revista de Ciências Sociais, vol. 54, no 2, pp. 289-318.

. (2011b), "Disciplina Partidária e Apoio ao Governo no Bicameralismo Brasileiro". Revista de Sociologia e Política, vol. 19, no 39, pp. 183-196.

; IZUMI, Mauricio. (2012), “Os ‘Doutores’ da Federação: Formação Acadêmica dos Senadores Brasileiros e Variáveis Associadas". Revista de Sociologia e Política, vol. 20, no 41, pp. 171-192.

NOKKEN, Timothy. (2000), "Dynamics of Congressional Loyalty: Party Defection and Roll-Call Behavior, 1947-97". Legislative Studies Quarterly, vol. 25, no 3, pp. 417-444.

NOKKEN, Timothy; POOLE, Keith. (2004), “Congressional Party Defection in American History". Legislative Studies Quarterly, vol. 29, no 4, pp. 545-568.

PEREIRA, Carlos; MUELLER, Bernardo. (2002), “Comportamento Estratégico em Presidencialismo de Coalizão: As Relações entre Executivo e Legislativo na Elaboração do Orçamento Brasileiro". DADOS - Revista de Ciências Sociais, vol. 45, no 2, pp. 265-301.

PEREIRA, Carlos; MUELLER, Bernardo. (2003), "Partidos Fracos na Arena Eleitoral e Partidos Fortes na Arena Legislativa: A Conexão Eleitoral no Brasil". DADOS - Revista de Ciências Sociais, vol. 46, no 4, pp. 735-771.

POOLE, Keith. (2000), "Nonparametric Unfolding of Binary Choice Data". Political Analysis, vol. 8, no 3, pp. 211-237.

(2005), Spatial Models of Parliamentary Voting. Cambridge, Cambridge University Press.

; ROSENTHAL, Howard. (1985), “A Spatial Model for Legislative Roll Call Analysis". American Journal of Political Science, vol. 29, no 2, pp. 357-384.

. (1991), "Patterns of Congressional Voting". American Journal of Political Science, vol. 35, no 1, pp. 228-278.

(2007), Ideology and Congress. New Jersey, Transaction Pub.

RICCI, Paolo. (2003), “O Conteúdo da Produção Legislativa Brasileira: Leis Nacionais ou Políticas Paroquiais". DADOS-Revista de Ciências Sociais, vol. 46, no 4, pp. 699-734.

ROSENTHAL, Howard; Voeten, Erik. (2004), “Analyzing Roll Calls with Perfect Spatial Voting: France1946-1958". American Journal of Political Science, vol. 48, № 3, pp. 620-632.

SAMUELS, David. (2003), Ambition, Federalism, and Legislative Politics in Brazil. Cambridge, Cambridge University Press.

;SNYDER, Richard. (2001), "The Value of a Vote: Malapportionment in Comparative Perspective". British Journal of Political Science, vol. 31, no 4, pp. 651-671.

SANTOS, Fabiano. (2003), O Poder Legislativo no Presidencialismo de Coalizão. Belo Horizonte, UFMG Editora. 


\section{Mauricio Yoshida Izumi}

SHOR, Boris; BERRY, Christopher; MCCARTY, Nolan. (2010), “A Bridge to Somewhere: Mapping State and Congressional Ideology on a Cross-Institutional Common Space". Legislative Studies Quarterly, vol. 35, no 3, pp. 417-448.

SPIRLING, Arthur; MCLEAN, Iain. (2007), "UK OC OK? Interpreting Optimal Classification Scores for the U.K. House of Commons". Political Analysis, vol. 15, no 1, pp. 85-96.

STEPAN, Alfred. (1999), "Para uma Nova Análise Comparativa do Federalismo e da Democracia: Federações que Restringem ou Ampliam o Poder do Demos". DADOS Revista de Ciências Sociais, vol. 42, no 2, pp. 197-251.

STRATMANN, Thomas. (2000), "Congressional Voting over Legislative Careers: Shifting Positions and Changing Constraints". American Political Science Review, vol. 94, no 3, pp. 665-676.

TSEBELIS, George; MONEY, Jeannette. (1997), Bicameralism. Cambridge, Cambridge University Press.

ZUCCO, César. (2009), “Ideology or What? Legislative Behavior in Multiparty Presidential Settings". The Journal of Politics, vol. 71, no 3, pp. 1076-1092.

. (2013), "Legislative Coalitions in Presidential Systems: The Case of Uruguay". Latin American Politics and Society, vol. 55, no 1, pp. 96-118. 


\section{Lista de Siglas dos Partidos Políticos}

DEM - Democratas

PCB - Partido Comunista Brasileiro

PCdoB - Partido Comunista do Brasil

PDS - Partido Democrático Social

PDT - Partido Democrático Trabalhista

PFL - Partido da Frente Liberal

PL - Partido Liberal

PMDB - Partido do Movimento Democrático Brasileiro

PP - Partido Progressista

PPS - Partido Popular Socialista

PR - Partido da República

PRB - Partido Republicano Brasileiro

PRN - Partido da Reconstrução Nacional

PSB - Partido Socialista Brasileiro

PSDB - Partido da Social Democracia Brasileira

PSOL - Partido Socialismo e Liberdade

PT - Partido dos Trabalhadores

PTB - Partido Trabalhista Brasileiro

PV - Partido Verde 


\section{Mauricio Yoshida Izumi}

\section{Anexo 1}

\section{Coalizões}

\begin{tabular}{|c|c|c|}
\hline Legislatura & Coalizão & Partidos da Coalizão \\
\hline $48^{\mathrm{a}}(1989-1990)$ & $\begin{array}{l}\text { Sarney } 2 \\
\text { Collor } 1 \\
\text { Collor } 2 \\
\end{array}$ & $\begin{array}{l}\text { PMDB - PFL } \\
\text { PRN - PFL } \\
\text { PRN - PFL - PDS }\end{array}$ \\
\hline $49^{\mathrm{a}}(1991-1994)$ & $\begin{array}{l}\text { Collor } 3 \\
\text { Collor } 4 \\
\text { Itamar } 1 \\
\text { Itamar } 2 \\
\text { Itamar } 3 \\
\end{array}$ & $\begin{array}{l}\text { PRN - PFL - PDS } \\
\text { PRN - PFL - PDS - PTB - PL } \\
\text { PFL - PTB - PMDB - PSDB - PSB } \\
\text { PFL - PTB - PMDB - PSDB - PP } \\
\text { PFL - PMDB - PSDB - PP }\end{array}$ \\
\hline $50^{\mathrm{a}}(1995-1998)$ & $\begin{array}{l}\text { FHC I } 1 \\
\text { FHC I } 2 \\
\end{array}$ & $\begin{array}{l}\text { PSDB - PFL - PMDB - PTB } \\
\text { PSDB - PFL - PMDB - PTB - PP }\end{array}$ \\
\hline $51^{\text {a }}(1999-2002)$ & $\begin{array}{l}\text { FHC II } 1 \\
\text { FHC II } 2 \\
\end{array}$ & $\begin{array}{l}\text { PDSB - PFL - PMDB - PP } \\
\text { PSDB - PMDB - PP }\end{array}$ \\
\hline $52^{-}(2003-2006)$ & $\begin{array}{l}\text { Lula I } 1 \\
\text { Lula I } 2 \\
\text { Lula I } 3 \\
\text { Lula I } 4 \\
\text { Lula I } 5\end{array}$ & $\begin{array}{l}\text { PT - PL - PCdoB - PSB - PTB - PDT - PPS - PV } \\
\text { PT - PL - PCdoB - PSB - PTB - PPS - PV - PMDB } \\
\text { PT - PL - PCdoB - PSB - PTB - PV - PMDB } \\
\text { PT - PL - PCdoB - PSB - PTB - PMDB } \\
\text { PT - PL - PCdoB - PSB - PTB - PMDB - PP }\end{array}$ \\
\hline $53^{-}-(2007-2010)$ & $\begin{array}{l}\text { Lula II } 1 \\
\text { Lula II } 2\end{array}$ & $\begin{array}{l}\mathrm{PT}-\mathrm{PL}-\mathrm{PCdoB}-\mathrm{PSB}-\mathrm{PTB}-\mathrm{PMDB}-\mathrm{PP} \\
\mathrm{PT}-\mathrm{PR}-\mathrm{PCdoB}-\mathrm{PSB}-\mathrm{PTB}-\mathrm{PMDB}-\mathrm{PP}-\mathrm{PRB}\end{array}$ \\
\hline
\end{tabular}

Fonte: Banco de dados legislativos (Cebrap) e Figueiredo (2011). 


\section{RESUMO}

Governo e Oposição no Senado Brasileiro (1989-2010)

Este artigo tem por objetivo avaliar o comportamento em votações nominais dos senadores brasileiros entre 1989 e 2010 . A questão central a ser respondida é quantas e quais dimensões são necessárias para representar razoavelmente bem as preferências de nossos senadores. Mostraremos que uma só dimensão que expressa o conflito entre governo e oposição é suficiente. Para verificar isso, utilizaremos técnicas de estimação de pontos ideais baseadas na teoria espacial do voto. Em particular, defenderemos o uso do método não paramétrico "optimal classification".

Palavras-chave: Legislativo; Senado; estimação de pontos ideais; Optimal Classification; coalizão

\section{ABSTRACT}

Government and Opposition in the Brazilian Senate (1989-2010)

This article's aim is to evaluate the behavior in role-call votes of Brazilian senators between 1980 and 2010. The central issue to be responded is how many and which dimensions are necessary to reasonably represent the preferences of our senators. The authors show that a single dimension expressing the conflict between government and opposition is sufficient. In order to verify this, techniques estimating the ideal points based on the spatial theory of votes are employed as well as the non-parametric optimal classification method.

Keywords: Legislative; Senate; estimation of ideal points; Optimal Classification; coalition 


\section{Mauricio Yoshida Izumi}

\section{RÉSUMÉ}

Gouvernement et Opposition au Sénat Brésilien (1989-2010)

Cet article a pour but d'analyser le comportement des sénateurs brésiliens lors des scrutins publics tenus entre 1989 et 2010. La question centrale à laquelle il s'agit de répondre est de savoir quelles sont les dimensions nécessaires à la représentation raisonnable des préférences de nos sénateurs. Nous montrerons qu'une seule dimension exprimant le conflit entre gouvernement et opposition est suffisante. Pour vérifier cet état de fait, nous avons utilisé des techniques d'estimation des points idéaux basées sur la théorie spatiale du vote. Nous nous appuierons en particulier sur l'usage d'une méthode non paramétrique du type "optimal classification".

Mots-clés: pouvoir législatif; Sénat; estimation des points idéaux; Optimal Classification; coalition

\section{RESUMEN}

\section{Gobierno y Oposición en el Senado Brasileño (1989-2010)}

Este artículo tiene como objetivo analizar el comportamiento en votaciones nominales de los senadores brasileños entre 1989 y 2010. La cuestión central a ser respondida es la siguiente: ¿cuántas y cuáles dimensiones son necesarias para representar razonablemente bien las preferencias de nuestros senadores? Mostraremos que sólo una dimensión que expresa el conflicto entre el gobierno y la oposición es suficiente. Para verificar esa asertiva, utilizaremos técnicas de estimación de puntos ideales basadas en la teoría espacial del voto y defenderemos el uso del método no paramétrico del tipo "optimal classification".

Palabras clave: legislativo; senado; estimativa de puntos ideales; Optimal Classification; coalición 